IZA DP No. 5682

Did the 2007 Legal Arizona Workers Act Reduce the State's Unauthorized Immigrant Population?

Sarah Bohn

Magnus Lofstrom

Steven Raphael

April 2011 


\title{
Did the 2007 Legal Arizona Workers Act Reduce the State's Unauthorized Immigrant Population?
}

\author{
Sarah Bohn \\ Public Policy Institute of California \\ Magnus Lofstrom \\ Public Policy Institute of California \\ and IZA \\ Steven Raphael \\ University of California, Berkeley \\ and IZA

\section{Discussion Paper No. 5682 \\ April 2011} \\ IZA \\ P.O. Box 7240 \\ 53072 Bonn \\ Germany \\ Phone: +49-228-3894-0 \\ Fax: +49-228-3894-180 \\ E-mail: iza@iza.org
}

\begin{abstract}
Any opinions expressed here are those of the author(s) and not those of IZA. Research published in this series may include views on policy, but the institute itself takes no institutional policy positions.

The Institute for the Study of Labor (IZA) in Bonn is a local and virtual international research center and a place of communication between science, politics and business. IZA is an independent nonprofit organization supported by Deutsche Post Foundation. The center is associated with the University of Bonn and offers a stimulating research environment through its international network, workshops and conferences, data service, project support, research visits and doctoral program. IZA engages in (i) original and internationally competitive research in all fields of labor economics, (ii) development of policy concepts, and (iii) dissemination of research results and concepts to the interested public.
\end{abstract}

IZA Discussion Papers often represent preliminary work and are circulated to encourage discussion. Citation of such a paper should account for its provisional character. A revised version may be available directly from the author. 


\section{ABSTRACT \\ Did the 2007 Legal Arizona Workers Act Reduce the State's Unauthorized Immigrant Population?*}

We test for an effect of Arizona's 2007 Legal Arizona Workers Act (LAWA) on the proportion of the state population characterized as foreign-born, as non-citizen, and as non-citizen Hispanic. We use the synthetic control method to select a group of states against which the population trends of Arizona can be compared. We document a notable and statistically significant reduction in the proportion of the Arizona population that is foreign-born and in particular, that is Hispanic noncitizen. The decline observed for Arizona matches the timing of LAWA's implementation, deviates from the time series for the chosen synthetic control group, and stands out relative to the distribution of placebo estimates for the remainder of states in the nation. Furthermore, we do not observe similar declines for Hispanic naturalized citizens, a group not targeted by the legislation. Our results on LAWA's impact on the housing market provide further support for our findings.

JEL Classification: J8, J11, J15, J18, J48, J61

Keywords: illegal, unauthorized, undocumented, immigration, Hispanic, Arizona

Corresponding author:

Magnus Lofstrom

Public Policy Institute of California (PPIC)

500 Washington Street, Suite 600

San Francisco, CA 94111

USA

E-mail: lofstrom@ppic.org

\footnotetext{
* We gratefully acknowledge the support of the Russell Sage Foundation. We also like to thank Judith Gans, Hans Johnson, Heather Koball, Ethan Lewis, Albert Liu, Marie Mora, David Neumark, Pia Orrenius, Jeffrey Passel, Karthick Ramakrishnan, Marc Rosenblum, and participants at the San Francisco Federal Reserve Bank's 2010 Applied Micro Conference, the Population Association of America's 2010 Annual Meeting, the Association for Public Policy Analysis \& Management's 2010 Annual Meeting, the American Economic Association's 2011 Annual Meeting and the IZA Workshop on Legal and Illicit Immigration for helpful feedback.
} 


\section{Introduction}

Along with the large increase in the foreign-born population residing in the United States, there has been a concurrent increase in the size of the unauthorized immigrant population. Since the 1986 passage of the Immigration Reform and Control Act (IRCA) (legislation that adjusted the legal status of most unauthorized immigrants in the U.S. at the time) the undocumented immigrant population subsequently grew to approximately 3 million in 1990 and to roughly 11 million by 2009 (Passel and Cohn 2010). Since 1986, there has been no comprehensive federal legislation intended to address the issue of unauthorized immigration, aside from efforts to strengthen border enforcement and executive branch driven surges in the enforcement of IRCA. In fact, the country finds itself in much the same position that it did in 1986. There is a strong desire to gain control of immigrant flows into the country and to discourage future unauthorized immigration.

The last few years have witnessed a sea of change in the traditional relationship between federal and state governments when it comes to immigration policy. Absent new federal law, several states have passed legislation meant to control and deter unauthorized immigrants within their jurisdiction. The provisions of these state laws vary, with some requiring that state contractors verify the identity and the eligibility to work of all employees and others making unauthorized employment a felony. The intention of these laws is to increase the costs to employers and undocumented immigrants of unauthorized employment and to shift labor demand to authorized workers. Proponents of such state legislation argue that strict enforcement should improve the labor market prospects of low-skilled natives and similar legal foreign residents. 
Arguably the most restrictive of such state legislation currently in place is Arizona's Legal Arizona Workers Act (LAWA). LAWA was passed in July 2007 and implemented in January 2008. The law requires all employers to verify the identity and work eligibility of all new hires using the federal E-verify system, an online system that checks an individual's information against Social Security Administration (SSA) and Department of Homeland Security (DHS) databases. Employers who fail to comply face the loss of their business licenses. In this paper, we assess whether the passage and implementation of LAWA has altered the demographic composition of the resident population of Arizona.

Prior to the law’s passage, a sizable minority of the Arizona population was foreign-born (approximately 16 percent), with roughly 10 percent of the population non-citizen Hispanic, a subgroup containing a large fraction of unauthorized immigrants in the state. To the extent that undocumented immigrants responded to the law by moving away from Arizona or future undocumented immigration to the state was deterred by the legislation, these proportions should decline. This internal compositional change may be further augmented by legal immigrants and perhaps the naturalized foreign-born leaving the state due to a change in perceived hostility towards immigrants or statistical discrimination on the part of employers.

We test for an effect of LAWA on the proportion of the state population characterized as foreign-born, as non-citizen, and as non-citizen Hispanic, groups with successively higher proportions of unauthorized immigrants. We use the synthetic control method developed by Abadie et. al. (2010) to select a group of states against which the population trends of Arizona can be compared. There are notable pre-post LAWA declines in the proportion of the population foreign-born, with much of the decline concentrated among non-citizen Hispanics. Our estimates range from declines of one and a half to two percentage points. The results from a 
series of permutation tests that estimate placebo treatment effects for all states with no changes in immigration legislation corresponding in time with LAWA show that Arizona is consistently an outlier. In nearly all such tests, the estimated relative decline in the Arizona foreign-born population is the largest. To probe the robustness of these results, we perform a series of additional tests. First, we assess whether there are comparable declines in the proportion of Arizona residents that are Hispanic naturalized citizens, a population whose employment prospects are not restricted by the legislation given that they are, by definition, authorized to work in the U.S. We find no evidence of a relative decline in this population. We also demonstrate that our results are robust to alternative definitions of the post-treatment period and are not being driven by spillover of population into neighboring states. We test for differential effects of the legislation on immigrants at different points in the age distribution. We find the largest impacts for working age immigrants.

Finally, we look for an impact of the legislation on the Arizona housing market. Given that undocumented immigrants and the foreign-born are over-represented in rental housing, one would expect increases in rental vacancy rates as a result of LAWA-induced population loss but little impact on the vacancy rate for owner-occupied housing. Applying the synthetic control estimator to quarterly vacancy rate data, we find a large pre-post LAWA increase in rental vacancy rates but no corresponding changes in owner-occupied housing vacancy rates.

We argue that the synthetic control method yields causal estimates of LAWA's impact on population composition in Arizona. We provide evidence that the potential endogeneity of the policy change, the timing of the Great Recession, and other immigration enforcement measures do not confound the estimates in this case. 


\section{The Impact of State Immigration Law on Population Movement}

In recent years, there has been an unprecedented level of state legislative activity in the immigration policy domain. In 2009, state legislatures passed 333 immigration-related pieces of legislation, compared to only 38 during 2005. Regarding employment specifically, between 2005 and 2009, a total of 91 laws were enacted in 34 different states. ${ }^{1}$ Many of these laws mandate the use of the federal E-Verify system for certain subsets of employers and impose penalties on both undocumented immigrants working illegally as well as on the employers that hire them.

Colorado was the first state to pass such legislation. Colorado’s law requires any person or entity that has entered into a public contract with the state on or after August 2006 to certify that it has verified the legal status of all new hires using E-Verify. Similar laws or executive orders were enacted in Georgia in 2007, Rhode Island in 2008, Minnesota in 2008, Missouri in 2009, and Utah in 2009. South Carolina, Utah, and Mississippi have recently passed more expansive legislation that phases in an E-Verify mandate to all employers use according to firm size. In South Carolina, employers of all sizes are required to use E-Verify by July 2010. In Mississippi all employers will be required to use E-verify by July 2011. Utah’s mandate covers all employers with 15 or more employees as of July 2010. Oklahoma constitutes a special case. While the first phase of the legislation was scheduled to go into effect in November 2007, a court challenge has held up implementation. To date, Oklahoma has yet to implement the provisions of its bill.

Arizona enacted what is arguably the most comprehensive legislation in this realm. The Legal Arizona Workers Act (LAWA) was signed into law in July 2007. LAWA mandates the

\footnotetext{
${ }^{1}$ Statistics cited in this paragraph are obtained from National Conference of State Legislatures (2006-2010).
} 
use of E-Verify by all employers in Arizona to establish the identity and work eligibility of all new hires made after January 1, 2008. ${ }^{2}$ The law imposes sanctions on employers who "knowingly" hire unauthorized immigrants including a business license suspension for the first offense and revocation upon a second. To date, legal action taken against employers for violating the provision of LAWA has been quite rare. As of April 2010, more than two years after implementation, only three employers have been indicted under the provisions of LAWA, and all of those in a single county (Maricopa). ${ }^{3}$ This lack of sanctioning activity may reflect either weak enforcement of the law or a high degree of compliance on the part of Arizona employers.

Employers in Arizona are increasingly using E-Verify. In the state, the number of employers registered with E-Verify increased from less than 300 in March 2007 to over 38,000 in January 2010. ${ }^{4}$ Arizona's enrollment is estimated to represent over one-third of all employers nationwide registered in the system and at least one-quarter of all employers in the state. ${ }^{5}$ Arizona's employers are more than twenty times more likely to enroll than employers in California, another state with a large unauthorized immigrant population. ${ }^{6}$ Thus LAWA appears to have had an initial, sizeable impact on employer enrollment in E-Verify. Recent reports suggest that at least 700,000 new hires made between October 2008 and September 2009 were subject to E-Verify checks in Arizona. ${ }^{7}$ This correlates to roughly 50\% of all new hires. Given this relatively high rate of usage as well as the high rate of enrollment, the potential effects of

\footnotetext{
${ }^{2}$ Note that LAWA predates Arizona's more recent and even more widely debated law, SB 1070 of 2010, which more directly targets immigrants themselves rather than employers. Given that we measure the effects of LAWA in years completely predating passage of SB 1070, we do not expect that legislation to be driving our results.

${ }^{3}$ Los Angeles Times (April 19, 2010).

${ }^{4}$ Westat (2009) and Arizona Attorney General's Office (2010), respectively.

${ }^{5}$ Westat (2009), fraction nationwide as of June 2008, and Rosenblum (2009), fraction in Arizona as of February 2009.

${ }^{6}$ Rosenblum (2009).

${ }^{7}$ Berry, Jahna (Aug 17, 2010) “Arizona’s ollegal immigrants can easily avoid E-Verify system”. The Arizona Republic.
} 
LAWA are sizeable. Furthermore, given these enrollment figures and the lack of sanctioning activity, we expect any observed effects to stem primarily from deterrence.

LAWA is distinctive among recent state legislation in that it was applied to all firms, rather than only those with public contracts, and all at once, rather than being phased in by firm size. In addition, sufficient time has passed to permit evaluation of the laws impact on population and economic outcomes. Importantly, Arizona has a large population of unauthorized immigrants (Passel and Cohen 2009a, 2009b).

To the extent that LAWA has made it more difficult for unauthorized immigrants to find work in Arizona, one would expect this to be reflected in the internal composition of state residents. Specifically, those planning to migrate illegally to Arizona may have decided to migrate elsewhere. Thus, undocumented migration may have contributed less to net population growth since the passage of LAWA than it would have in the absence of the legislation. Second, some portion of the undocumented immigrant population residing in Arizona prior to the passage and implementation of LAWA may have chosen to leave due to perceived and/or actual increases in the difficulty of finding employment.

Aside from reductions in the undocumented immigrant population, the legislation may also induce legal immigrants and perhaps some native-born to leave the state. This could occur through several channels. Some legal immigrants, naturalized citizens, and native born may have family members (spouses, parents, siblings etc) who are undocumented. Given that interregional mobility often involves entire households, and sometimes multiple households, some individuals legally authorized to work in the U.S. may leave Arizona along with their undocumented family members and intimates. 
A further impetus to migration might occur through an increase in the difficulty finding employment among immigrants who are legally eligible to work in the U.S. This might occur due to an increased in statistical discrimination by employers against immigrants or those with Hispanic surnames. Alternatively, the E-verify system may in and of itself create more problems for the legal foreign-born. The system essentially compares the name and social security numbers of new hires against existing SSA and DHS records. If a match between provided information and the administrative records cannot be made, then the E-verify system returns a report of non-confirmation to the employer. A formal evaluation of E-verify by Westat (2007) found that less than 1 percent of natives but almost 10 percent of foreign-born U.S. citizens received an erroneous non-confirmation of work authorization. To the extent that such nonconfirmations make it more difficult to find and hold employment, legal foreign-born residents of Arizona may have an incentive to move elsewhere.

To be sure, aside from migration LAWA may impact undocumented immigrants that choose to remain in the state. In particular, increased difficulty finding formal employment may lead to declining employment-to-population ratios or shifts towards informal work. The law may also impact the degree to which remaining undocumented workers engage the state in other domains (reporting crime and victimization to the police, using emergency room services in county hospitals, enrolling children in school etc). While these are certainly important topics for investigation, in this initial study we focus our efforts on assessing the laws impacts on aggregate population movements. 


\section{Empirical Methodology and Data Description}

To assess the impact of LAWA on the internal composition of Arizona's resident population, we analyze data from all monthly Current Population Survey (CPS) data sets collected between January 1998 and December 2009. We combine files within years and estimate the proportion of residents that is foreign-born, that is non-citizen, and that is noncitizen Hispanic. Ideally, we would like to identify the proportion undocumented among the state population. However information on legal immigration status is not available in the CPS, or any suitable data source. Nonetheless, the proportion undocumented is certainly greater among non-citizens than the foreign-born more generally and even greater still among Hispanic non-citizens. Hence, by comparing trends among these nested population groups, we can assess whether any population shift is most likely driven by net out-migration of the undocumented. ${ }^{8}$

Table 1 describes trends in these population groups for the period from 1998 to 2009. Recall, LAWA is passed in mid 2007 and implemented in January 2008. Hence, the last two years constitute the post-treatment periods while population responses in 2007 are possible through migration in anticipation of LAWA's implementation. The proportion of Arizona residents that is foreign-born exhibits considerable stability between 1998 and 2006, increasing from 15 percent to 16.1 percent over this period. Beginning in 2007, the proportion foreign-born begins to decline reaching 14.3 percent by 2009 (a decline relative to 2006 of 1.8 percentage points). Turning to the sub-category of the foreign-born who are non-citizens, we observe a similar overall trend prior to 2006 although the increase in the proportion of Arizona residents

\footnotetext{
${ }^{8}$ Estimates suggest that as of 2009, 80\% of unauthorized immigrants nationwide were Hispanic, 58\% were between the ages of 18-39, and the majority have fewer years of formal education (Passel and Cohn, 2010). In the subgroup of "likely unauthorized" defined as Hispanic non-citizen immigrants of working age with no more than a high school diploma, we estimate that $90 \%$ in Arizona were unauthorized. For example, our calculations from the 2008 American Community Survey indicate that roughly 517,000 non-citizen Hispanic immigrants resided in Arizona in 2008. For this same year, Passel and Cohn (2009) estimate that there were 475,000 unauthorized immigrants in the state. Similarly, for the "likely unauthorized" subgroup mentioned above, we estimate that 229,000 were in the labor market in Arizona in 2008 compared to the Passel and Cohn (2009) estimate of 240,000.
} 
that are non-citizens is greater than the increase in the proportion foreign-born. In addition, the post-2006 decline in this variable (of 2.6 percentage points) exceeds the decline for the overall proportion foreign-born. Population trends among Hispanic non-citizens are similar. There are slight increases in the proportion of the Arizona population described by this category between 1998 and 2006. Post 2006, we observe a decline of 2.6 percentage points.

The CPS inquires about the highest level of completed education for individuals 15 years and older. Table 1 also present estimates of trends in the proportion of the state population 15 years and older that falls into categories defined by nativity/immigration/Hispanic status and the level of educational attainment. Looking first at the foreign-born category, we only observe post-LAWA declines in the proportion who are foreign-born and who have less than a high school degree. Regarding the non-citizen category, the proportion of state residents that are noncitizen and have less than a high school degree declines by 1.3 percentage points between 2006 and 2009, while the proportion with a high school degree declines by 0.6 percentage points. There is no measurable decline among non-citizens with higher levels of schooling. Similar patterns are observed when we restrict the focus to Hispanic non-citizens.

Hence, there is a notable pre-post decline in the proportion of Arizona residents that are foreign-born, with much of this decline attributable to declines in the population of Hispanic non-citizens. Moreover, while the trends by educational attainment pertain to a subset of the Arizona population (those 15 and older), these more detailed calculations suggest that much of the relative population decline among the foreign-born was concentrated among relatively less educated immigrants. As all three of these traits - non-citizen, Hispanic, and lower levels of educational attainment - are predictive of undocumented status (Passel and Cohen 2009a, 
2009b), the raw patterns in Table 1 are consistent with a population response on the part of the undocumented to LAWA's passage.

To assess whether the observed relative population declines of the foreign-born are being driven by a response to LAWA, we need to identify a comparison state or states that we can use to chart the counterfactual path of population trends for Arizona. There are several strategies for constructing such a comparison group. One possibility would be to select states that one could reasonably argue share similar population and economic characteristics; for example, all states bordering Arizona. Comparable arguments could be made for using all states that share a border with Mexico. An alternative strategy would be to employ a data-driven search for a comparison group based on pre-LAWA population characteristics and trends. Here, we pursue this latter tack. ${ }^{9}$

We employ the synthetic control method developed by Abadie et. al. (2010) to chart a counterfactual post-LAWA path for Arizona. Specifically, let the index $\mathrm{j}=(0,1, \ldots, \mathrm{J})$ denote states. The value $\mathrm{j}=0$ corresponds to Arizona and $\mathrm{j}=(1, \ldots, \mathrm{J})$ correspond to each of the other $\mathrm{J}$ states that are candidate contributors to the control group (or in the language of Abadie et. al, the donor pool). Define $F_{0}$ as a $9 \mathrm{x} 1$ vector with elements equal to the proportion of the Arizona population that is foreign-born in years 1998 through 2006 (the nine years we use throughout this paper as our pre-intervention period). Similarly, define the 9xJ matrix $F_{1}$ as the collection of comparable time series for each of the $\mathrm{J}$ states in the donor pool (with each column corresponding to a separate state-level time series for the period 1998 through 2006).

The synthetic control method identifies a convex combination of the $\mathrm{J}$ states in the donor pool that best approximates the pre-intervention time series for the treated state. Define the Jx1

\footnotetext{
${ }^{9}$ We also conducted a traditional difference-in-difference approach with hand-selected comparison states and found similar results.
} 
weighting vector $W=\left(w_{1}, w_{2}, \ldots, w_{J}\right)$ ' such that $\sum_{j=1}^{J} w_{j}=1$, and $w_{j} \geq 0$ for $\mathrm{j}=(1, \ldots, \mathrm{J})$. The product $F_{1} W$ then gives a weighted average of the pre-intervention time series for all states omitting Arizona, with the difference between Arizona and this average given by $F_{0}-F_{1} W$. The synthetic control method essentially chooses a value for the weighting vector, $W$, that yields a synthetic comparison group (consisting of an average of some subset of donor states) that best approximates the pre-intervention path for Arizona. Specifically, the weighting vector is chosen by solving the constrained quadratic minimization problem

$$
W^{*}=\arg \min _{W}\left(F_{o}-F_{1} W\right)^{\prime} V\left(F_{0}-F_{1} W\right)
$$

s.t.

$$
W^{\prime} i=1, \quad w_{j} \geq 0, \quad \text { for } \quad j=(1, \ldots, J)
$$

where $\mathrm{V}$ is a 9x9, diagonal positive-definite matrix with diagonal elements providing the relative weights for the contribution of the square of the elements in the vector $F_{0}-F_{1} W$ to the objective function being minimized. ${ }^{10}$

Once an optimal weighting vector $W^{*}$ is chosen, both the pre-intervention path as well as the post-intervention values for the dependent variable in "synthetic Arizona" can be tabulated by calculating the corresponding weighted average for each year using the donor states with positive weights. The post-intervention values for the synthetic control group serve as our counterfactual outcomes for Arizona.

\footnotetext{
${ }^{10}$ The Stata procedure developed by Abadie et. al. (2010) uses as the default a regression-based measure of V where those matching variables that are strong predictors of the dependent variable are given more weight and where the elements of V are normalized such that they sum to one. Since we are matching on all pre-intervention annual values of the dependent variables, this default matrix provides fairly equal weight on the match for each year. We have estimated all of these models constraining the weights in $\mathrm{V}$ to being equal (i.e., set $\mathrm{V}=\mathrm{I}$ ) across pre-intervention values and have also estimated fully nested models that choose both optimal values of $\mathrm{V}$ as well as $\mathrm{W}$ (as in Abadie and Gardeazabal 2003). As the results were virtually indistinguishable from the results using the program's default $\mathrm{V}$, we report the default estimates throughout.
} 
Our principal estimate of the impact of LAWA on population outcomes uses the synthetic control group to calculate a simple difference-in-differences estimate. Specifically, define Outcome $_{p r e}^{A Z}$ as the average value of the outcome of interest for Arizona for the pre-intervention period 1998 through 2006 and Outcome $e_{\text {post }}^{A Z}$ as the corresponding average for the two posttreatment years 2008 and 2009. Define the similar averages Outcome $e_{\text {pre }}^{\text {synt }}$ and Outcome $e_{\text {post }}^{\text {synt }}$ for the synthetic control group. Our difference-in-differences estimate subtracts the pre-intervention difference between the averages for Arizona and synthetic Arizona from the comparable postintervention difference, or

$$
D D_{A Z}=\left(\text { Outcom } e_{\text {post }}^{A Z}-\text { Outcom } e_{\text {post }}^{\text {snth }}\right)-\left(\text { Outcome } e_{p r e}^{A Z}-\text { Outcom } e_{p r e}^{\text {snth }}\right) .
$$

To the extent that LAWA induced net migration of the foreign-born out of Arizona, one would expect to find that $\mathrm{DD}_{\mathrm{AZ}}<0$.

To formally test the significance of any observed relative decline in Arizona's foreignborn population, we apply the permutation test suggested by Abadie et. al. (2010) to the difference-in-difference estimator displayed in equation (2). ${ }^{11}$ Specifically, for each state in the donor pool, we identify synthetic comparison groups based on the solution to the quadratic minimization problem in equation (1). We then estimate the difference-in-difference in (2) for each state as if these states had passed the equivalent of a LAWA with comparable timing (passed in mid 2007 and implemented in January 2008). The distribution of these "placebo" difference-in-difference estimates then provides the equivalent of a sampling distribution for the estimate $\mathrm{DD}_{\mathrm{AZ}}$. To be specific, if the cumulative density function of the complete set of $\mathrm{DD}$

\footnotetext{
${ }^{11}$ Buchmueller, DiNardo and Valletta (2009) use a similar permutation test to that described here to test for an impact of Hawaii's employer-mandate to provide health insurance benefits to employees on benefits coverage, health care costs, wages and employment.
} 
estimates is given by $\mathrm{F}($.$) , the p-value from a one-tailed test of the hypothesis that \mathrm{DD}_{\mathrm{AZ}}<0$ is given by $\mathrm{F}\left(\mathrm{DD}_{\mathrm{Az}}\right)$.

In selecting a synthetic control group for Arizona, we omit from the donor pool four states with broadly applied (in terms of employer coverage) restrictions on the employment of undocumented immigrants (Mississippi, Rhode Island, South Carolina, and Utah). In addition, in identifying synthetic control groups for each of the remaining states in the donor pool, we omit Arizona. Since Arizona experiences sharp declines in the foreign-born population pre-post LAWA, omitting Arizona from the donor pool for estimating the placebo intervention effects should impart a negative bias to these placebo estimates (a specification choice that should make it more difficult for us to find a significant effect).

Table 2 displays the states receiving positive weights in the construction of synthetic Arizona for our three outcomes of interest (essentially, the positive elements in the solution vector $\left.W^{*}\right)$. As can be seen, the states contributing to the synthetic control group as well as the weights assigned across states varies across the dependent variables. For the proportion foreignborn, seven states receive positive weights, with much weight going to traditional immigrant receiving states with relatively little weight on neighboring southwestern states. The solution weighting vector for the proportion non-citizen places positive weight on five states, with considerably weight placed on California (almost half). When we focus on Hispanic noncitizens the lion's share of weight is placed on California (0.747) with the remaining weight roughly split between North Carolina and Maryland. 


\section{Validating the Identification Strategy}

Our empirical strategy requires that the enactment of LAWA represents an exogenous shock to the labor market. For example, if high unemployment among the foreign born and the attendant problems led states to enact legislation attempting to discourage future migration to the state, any inference on the effect of such legislation on labor market outcomes would be compromised. In fact, LAWA was debated and passed during a period of economic growth but was enacted at a time of declining labor market conditions in Arizona.

A number of facts suggest that the passage and enactment of LAWA was not driven by employment conditions in the state at the time but instead reflected Arizona's perceived longterm problem of unauthorized immigration, also experienced by other states. To start, LAWA represents the ultimate manifestation of a fairly lengthy legislative debate that crossed multiple legislation sessions. Moreover, there was considerable uncertainty as to whether LAWA would be enacted on January 1, 2008. Federal lawsuits challenging the constitutionality of LAWA were brought by an alliance of civil rights advocates, business interests and immigrant rights groups. The challenge was dismissed, but not until early December. Anecdotal evidence suggests that those likely to be affected by actual implementation followed the court challenge and were conditioning their responses on the ultimate legal outcome (see The Arizona Republic, October 8, 2007).

Although Arizona's employment legislation has the potential to impact the labor market, a number of other forces also drive those conditions. Under the synthetic control approach, unless the timing of these other forces was coincident with that of LAWA, we argue that our estimates represent the causal relationship between LAWA and Arizona's population. This argument hinges on the ability of the synthetic control method to (1) match Arizona's pre- 
LAWA trends with those of other states and (2) determine whether Arizona's pre-post changes stand out from the placebo estimates for all other states. We will show in the following section that both of these conditions are satisfied. Given that, we need only address the two major factors coincident with LAWA that could potentially invalidate the claim of causality.

First, we are concerned about the potential coincidence of federal immigration enforcement increases with the enactment of LAWA. We have reviewed DHS data and have found nothing to suggest that federal enforcement increases at the border or in internal investigations happened differentially in Arizona than in other border states and/or happened at exactly the same time. The Arizona Border Control Initiative, which built up infrastructure on Arizona's border with Mexico predated LAWA by a few years. Further, our review of DHS arrest and apprehension data suggests that a similar percentage of all border apprehensions occurred in the Tuscon sector (about 42\%) following LAWA and the number of arrests resulting from ICE investigations actually fell (Office of Immigration Statistics, 2010).

Second, the "Great Recession" occurred at approximately the same time of the enactment of LAWA. There is evidence that the recession reduced the inflow of new immigrants to the US and new immigrants to Arizona. Our empirical approach comparing trends in Arizona to other states already accounts for any changes that affect the country as a whole (or the selected comparison states). However, one of the industries hit hardest, construction, is a leading employers of unauthorized immigrants. Furthermore, construction is one of the biggest industries in Arizona (representing close to 11 percent of total private employment in 2006) so the state's economy can be impacted significantly by declines therein. Thus, it is important in our evaluation strategy to ensure that we do not attribute changes in population to LAWA if they were in fact driven by the decline in construction and real estate in Arizona specifically. To 
validate our empirical approach, we assess official statistics on employment trends in Arizona and neighboring states during the recession.

The recent recession caused a clear reduction in Arizona’s workforce. Figure A1 shows strong employment growth 2003-2006 with a noticeable slow down in 2007. This was followed by three and eight percent decreases in 2008 and 2009, respectively. Figure 3 also shows that the negative employment effects of the recession on employment were not any stronger in Arizona than it was in neighboring areas, including inland California (an area that shares many of the characteristics and trends of Arizona, is hence used in our empirical analysis). Lastly, an application of the synthetic cohort method to employment growth fails to reveal a LAWA effect in Arizona.

Importantly, the recession was precipitated by a housing crisis, which brought new housing construction to a near standstill. The fact that many unauthorized immigrants are, or maybe more accurately were, employed in the construction sector means that they may have been particularly affected by the recession. However, a look at construction employment data reveals no evidence that Arizona's construction industry fared much differently in the recession than its neighboring areas (Figure A2).

Overall, the data indicates that while Arizona's labor market was strongly affected by the recession, so were other states', including its neighbors. The similarity in trends indicates that our empirical strategy is appropriate for identifying causality despite the recent recession. 


\section{Basic Results}

We begin with a graphical presentation of the Arizona population trends and the comparable population trends in synthetic Arizona for our three outcomes. Figures 1 through 3 present the proportion of each population that is foreign-born, that is noncitizen, and that is Hispanic non-citizen. Focusing first on the pre-intervention period 1998 through 2006, the figures reveal that population trends for the synthetic control groups closely match corresponding population trends in Arizona. Average pre-intervention differences between Arizona and the synthetic control groups are near zero for each outcome, with quite small root mean squared errors (.00197 for the proportion foreign-born, .00367 for the proportion non-citizen, and .00438 for the proportion non-citizen Hispanic). Hence, the synthetic control groups match the preintervention values for Arizona quite well for each of the outcomes.

Regarding the post-intervention period, for each of the outcomes we observe sizable gaps (on the order of one to 2.5 percentage points) between Arizona and the synthetic control groups. For the foreign-born outcome, the gap begins to open up in 2007 and widens in each year thereafter. For the proportion non-citizen and the proportion non-citizen Hispanic, the gaps relative to the synthetic controls do not widen until 2008, and are wider still by 2009 . Thus, the declines in the immigrant population observed in Arizona are not observed in states with comparable pre-LAWA population composition and dynamics.

Figures 4 through 6 graphically display the raw data needed to conduct the permutation test of the significance of the relative declines in Arizona. Specifically, for each of the 46 donor states as well as for Arizona, the figures display the year-by-year difference between the outcome variable for the "treated" state and the outcome variable for the synthetic control. The differences for each of the donor states are displayed with the thin black lines while the 
differences for Arizona are displayed by the (red) thick line. There are several notable patterns in these figures. First, during the pre-intervention period 1998 through 2006, the differences for Arizona clearly lie within the distribution of placebo estimates, suggesting that Arizona is not an outlier during this period. There are several states, California in particular, with very large preintervention differences relative to its synthetic control group. For California, this is driven by the fact that the state has the highest values for the dependent variables of all states in the donor pool, and hence it is impossible to match the state with a convex combination of other states.

Second, for the post intervention years as the difference values for Arizona turn negative, Arizona moves to the bottom of the distribution in each graph. By 2009 the state becomes a visible outlier. This pattern is observed for all three outcome variables, with the departures for Arizona particularly large in absolute value for non-citizens and Hispanic non-citizens.

Table 3 presents estimates of the difference-in-differences estimator laid out in equation (2) above. For each outcome, the first column presents the mean difference between Arizona and the synthetic control for all years in the interval 1998 through 2006. The second column presents the comparable average difference for 2008 and 2009 while the third column presents the difference-in-difference. The fourth column presents where Arizona's difference-indifference estimate ranks (with states ranked from lowest to highest) in the distribution created by combining the 46 placebo estimates for donor pool states with the estimate for Arizona. The final column presents the P-value from the one-tailed test of the null hypothesis that the relative change for Arizona is non-negative against the alternative that the difference-in-difference is negative. Note, this P-Value is bounded from below by 0.021 (1/47).

The results in panel A show the estimates based on the entire resident population. For all three outcomes, the average difference relative to synthetic Arizona is basically zero in the pre- 
intervention period. For the proportion foreign-born, there is a relative decline for Arizona of 1.8 percentage points. Arizona's difference-in-difference estimate is the most negative, yielding the minimum P-value of 0.021. The outcome for the proportion non-citizen shows a difference-indifference estimate of 1.7 percentage points. Hence, the overwhelming share of the decline in the foreign born is driven by declines in the population of non-citizens. Again, the estimate for Arizona has the most negative value relative to the distribution of placebo estimates. Turning to the estimates for non-citizen Hispanics, the difference-in-differences estimate suggests a 1.5 percentage point decline in the proportion of Arizona residents that fall into this category. Again, the Arizona estimate is the most negative.

One can use the difference-in-difference estimates to calculate the net decline in population caused by the passage and implementation of LAWA. In terms of actual people, Arizona's population in 2006 stood at approximately 6.2 million. These estimates suggest a relative population loss of between 93,000 and 112,000.

Panel B of Table 3 presents comparable estimation results where the population is restricted to Arizona residents employed at a wage and salary job. Here relative declines in the foreign-born population can be driven either by residential mobility or a pre-post LAWA increase in the degree of difficulty experienced by foreign-born workers when looking for work. The patterns in Panel B are basically comparable to the results based on the entire resident population. The proportion foreign-born among the employed declines by 2.6 percentage points in Arizona relative to synthetic Arizona. The comparable estimate for non-citizens is 1.9 percentage points, while the estimate for non-citizen Hispanics is 1.8 percentage points. Again, the relative declines for Arizona are at the bottom of the distribution of placebo estimates for all of the states in the donor pool. Note, the estimated impacts on the relative representation of the 
foreign born (and the sub-populations therein) among the employed are larger than the corresponding estimates for the entire population. This may be driven by either a disemployment effect of LAWA that reduces the representation of the foreign born beyond the impact of net migration, or perhaps a differential migration effect for foreign-residents of working age. In the next section, we explore this in greater detail.

To summarize the results, we find pre-post LAWA declines in the representation of the foreign born among the Arizona resident population. Corresponding declines do not occur in the synthetic control group. Most of the decline is concentrated among non-citizens and non-citizen Hispanics. Moreover, we observe a decline in immigrant representation among those with jobs that exceeds the comparable decline among the state's resident population more generally. For all outcomes in both sets of estimates, the relative declines in Arizona fall in the extreme lower tail of the distribution of placebo estimates - i.e., the difference-in-difference estimates for Arizona are the most negative.

\section{Robustness Checks and Exploring Effect-Size Heterogeneity}

In this section, we probe the robustness of the main results and explore whether the population responses vary within sub-groups of the foreign-born population. Specifically, we first assess whether the estimation results are sensitive to the definition of the post-treatment period and the extent to which cross-state spillover may be biasing our difference-in-differences estimates. Second, we test for effects of LAWA on a series of alternative population and housing outcomes for which we have priors regarding the likely impact of the legislation. Finally, we assess whether the impact of LAWA on population movements varies by sub-groups of the immigrant population defined by age and gender. 


\section{A. Some specification checks}

We begin by exploring the sensitivity of the estimates to the definition of the posttreatment period. In Table 3, we define the post-period as calendar years 2008 and 2009 due to the fact that LAWA was implemented on January 1, 2008. One might contend that 2007 should be included as a post-treatment year as the legislation was passed mid-2007 and households may have migrated in anticipation of the law's passage and implementation. In all of the estimates that we have presented thus far, we have not matched the treatment to the synthetic controls with 2007 values and have omitted this year from our post-treatment period.

Panel A of Table 4 presents comparable estimates to those in Panel A of Table 3, but that include 2007 in the post-treatment period. Here we focus only on the results for all Arizona residents as we will explore age heterogeneity in greater detail below. The relative population declines for Arizona including the 2007 population are somewhat smaller (by 0.3 percentage points for the foreign-born outcome, by 0.9 percentage points for the noncitizen outcome, and by 0.6 percentage points for the noncitizen Hispanic outcome). However, it is still the case that the declines for Arizona are the largest when compared to the distribution of placebo estimates across the 46 potential donor states.

Clearly, 2007 is a problem year. One might expect an anticipatory effect prior to implementation and hence would not want to match on the 2007 value. However, any anticipatory effect should be small as the mandatory use of E-verify does not commence until January 2008 and since the enhanced verification requirement did not apply retroactively to past hires. This latter fact alone suggests that the proportion of pre-LAWA Arizona residents impacted by the law should increase with time and that the initial impact prior to implementation 
should be small. Based on this reasoning, we prefer the estimates in Table 3 that omit the 2007 values from any calculations.

An additional issue concerns potential bias caused by population spillover created by migration out of Arizona into other states across the nation. Specifically, Arizona's population loss may be due either to deterred future migration, foreign migrants leaving the country, or migrants leaving for other states. If the latter is an important contributor to state population among those states contributing to the synthetic control group, then the suitability of the posttreatment path for the synthetic control group in charting the counterfactual for Arizona is compromised. This might be a particularly important source of bias if migrants leave Arizona for California since California contributes disproportionately to the synthetic control group for each of the outcomes we analyze.

In the current application, there are several reasons to believe that such spillover is quantitatively unimportant. To start, the absolute declines in the proportion of the Arizona population that falls into our three categories are comparable in magnitude to the declines measured relative to the synthetic controls. For example, averaging the pre and post-intervention values in Table 1 using the period definitions employed in Table 3 shows an absolute decline in the proportion of Arizona residents that are foreign born of 1.4 percentage points (compared with our difference-in-difference estimate of 1.8 percentage points). The comparable absolute declines for foreign-born Hispanic and noncitizen Hispanics are 1.6 and 1.3 percentage points, respectively. Hence, the relative declines that we estimate in Table 3 are driven primarily by compositional changes in Arizona rather than compositional changes in the states contributing to the synthetic control groups. 
Second, Arizona is a small state. The impact of a modest population decline in Arizona on the population of neighboring states is bound to be small. For example, Arizona's 2007 population stood at approximately 6.25 million persons. Our difference-in-differences estimates suggest that the proportion foreign-born declined by 1.8 percentage points. Relative to 2007, this corresponds to a LAWA-induced absolute population loss of roughly 112,000. Suppose that the entire 112,000 foreign-born moved to neighboring California (the only state bordering Arizona that contributes to the synthetic control in any of our comparisons). Such a population move would increase the proportion of California residents that are foreign born from the actual value in 2007 of 0.283 to the hypothetical value of 0.286 . Moreover, since California never contributes more than 75 percent to the synthetic controls for any of our outcomes, the impact of such cross-border spillover on the post-treatment values for the synthetic control would be even smaller than what is implied by this hypothetical exercise.

Finally, when we restrict the donor pool to states that do not share a border with Arizona $^{12}$ the difference-in-difference estimates as well as the statistical inferences are quite similar to our estimates in Table 3. Since one might expect the largest effects of population spillover on the populations of neighboring states, omitting these states from the donor pool provides a key robustness check. These results are presented in Panel B of Table 4. Omitting the states that share any border with Arizona yields difference-in-difference estimates that are essentially the same as those that include these states in the donor pool (the estimates reported in Table 3). Moreover, the observed DD estimates for Arizona are still more negative than each of the remaining 43 placebo estimates for all three outcome variables.

\footnotetext{
${ }^{12}$ Throughout the analysis we have been omitting Utah from the donor pool due to the presence of comparable (yet not identical) state legislation. In the tabulations in Table 4 Panel B we further drop California, Colorado, Nevada, and New Mexico from the potential donor pool.
} 


\section{B. Testing for Effects of LAWA on Alternative Population and Population-Related Outcomes}

The enhanced employment verification requirements of LAWA are targeted specifically at foreign-born job seekers that are unauthorized to work in the United States. Thus, to the extent that there is a migratory response to the legislation, one would expect the largest population impact on groups with high proportions unauthorized. Conversely, while legal immigrants may also leave the state due to social connections with unauthorized immigrants, due to increased discrimination against all foreign-born, or due to a perceived increase in hostility towards immigrants, one would expect smaller population changes among the authorized. Hence, one key falsification check is to test for an impact of LAWA on the proportion of the Arizona population that is foreign born yet legally residing within the state.

In addition, a sudden change in population should have derivative impacts on other outcomes. Perhaps the most obvious place to look would be the Arizona housing market. As we will soon document, immigrants accounted for a relatively large share of households residing in rental housing in pre-LAWA Arizona. Moreover, the majority of the Arizona population resides in owner-occupied housing. In conjunction, these two facts suggest that a LAWA-induced population loss should have a larger impact on the market for rental housing than on the market for owner-occupied housing.

In this sub-section we present evidence pertaining to these falsification tests. We begin by testing for an impact of LAWA on the proportion of Arizona residents that are Hispanic, naturalized citizens. Figure 7 displays trends in the proportion that are Hispanic naturalized citizens for Arizona and for the synthetic control for Arizona for the period 1998 through 2009. Relatively few Arizona residents fall into this category, with the highest value for Arizona of approximately 0.03 in 2009. Despite a dip in this series in 2007, the proportion of Arizona 
residents that are Hispanic naturalized citizens appears roughly stable through the implementation of LAWA. Figure 8 displays the difference for each year between Arizona and the synthetic control group along with the placebo difference series for each of the 46 states in the donor pool. The drop in this variable in 2007 for Arizona certainly stands out. However, by 2009 the difference for Arizona lies well within the distribution of placebo estimates for the other states.

The first row of Table 5 presents the results from applying our difference-in-difference estimator to this particular dependent variable. For the period 1998 through 2006 the average difference between Arizona and its synthetic control group is zero. For the two post-intervention years (2008 and 2009), the difference widens slightly to -0.003 . This ranks fifth out of the 47 estimates yielding a P-value of the one-tailed test for a decline in this population variable of 0.106. Taken together with the patterns documented in Figures 7 and 8, there appears to be little evidence that naturalized Hispanics responded to LAWA by migrating from the state.

Regarding the Arizona housing market, prior to the passage of LAWA the foreign-born in Arizona were disproportionately concentrated in rental housing. Our tabulations of data from the 2006 American Community Survey (ACS) show that among Arizona households headed by the foreign-born, roughly 41 percent resided in rental housing compared with 28 percent of households headed by the native born. Among households headed by a noncitizen, 53 percent rent, while the comparable figure among households headed by a Hispanic noncitizen is 56 percent. The relatively high proportion of immigrants in rental housing combined with the fairly sizable foreign-born population in Arizona naturally implies that immigrants comprise a fairly large portion of the demand side in Arizona's market for rental housing. Indeed, in 2006 immigrant-headed households occupy over one fifth of the state's rental housing. The 
comparable figures for noncitizen and noncitizen Hispanic households are 17 and 14 percent, respectively.

Given the relative concentration of immigrants in rental housing, population losses on the order implied by our difference-in-difference estimates in Table 3 should disproportionately impact the Arizona rental market. Here we asses this proposition by testing for pre-post LAWA changes in the rental housing vacancy rate and the owner-occupied housing vacancy rate. To do so, we use quarterly vacancy rate data from the first quarter of 2005 through the last quarter of 2009 from the Current Population Survey/Housing Vacancy Survey (CPS/HVS). We apply the synthetic control procedure to these data to identify a rental vacancy series for synthetic Arizona and then use this series to calculate difference-in-difference estimates for these housing outcomes. Since we have quarterly data, we define the pre-intervention period as all quarters prior to quarter three 2007. To identify the states contributing to the synthetic control, we match on annual average vacancy rates for the pre-intervention period as well as the seasonal averages of these values (the average of the three quarter one values, the three quarter two values etc) to adjust for seasonal variability in vacancy rates. In addition, we match on a number of covariates that are likely predictors of housing market vacancy rates. In particular, we match on preintervention values of the proportion of state residents in metropolitan areas, the age distribution of state residents (proportion under 18, 18 to 29, 30 to 39, 40 to 49, 50 to 64, and 65 and over), the proportion nonwhite, the proportion Hispanic, the proportion foreign-born, the proportion poor, and the proportion that rent. We tabulate these covariates from the 2005 through 2007 American Community Survey.

Before discussing the estimates, it is instructive to work through a simple back-of-theenvelope calculation regarding the likely size of the impact one might expect from a sudden 
decline in the foreign-born population on housing vacancy rates. In 2006, renters account for 29.8 percent of Arizona households. Our main difference-in-difference estimate suggests that LAWA reduced the proportion of the Arizona population that is foreign born by 0.018 . If we assume that this translates into a 1.8 percentage point decline in the number of Arizona households ${ }^{13}$ and that the entirety of this decline occurs among rental households, then the rental vacancy rate should increase by 6.04 percentage points ([1.8/29.8]x100).

Figure 9 displays the quarterly rental vacancy rates for Arizona and the synthetic control for 2005 through 2009 (quarters are labeled relative to quarter three of 2007). There is a pronounced increase in rental vacancy rates starting in the first quarter of 2008 that progressively increases through 2009. There is no corresponding increase among the synthetic control group. Figure 10 displays the differences between Arizona and the synthetic control by quarter alongside the comparable differences for each of the 46 states in the donor pool. The time series for Arizona lies squarely within the placebo distribution pre-LAWA but becomes a clear outlier with the largest values post-implementation. Figures 11 and 12 present comparable graphs for the owner-occupied vacancy rates. In Figure 11 we observe similar post-LAWA trends in vacancy rates for Arizona and the synthetic control states. Moreover, relative to the 46 placebo estimates, the difference between Arizona and the synthetic controls (displayed in Figure 12) are not indicative of an impact of LAWA on this variable.

The last two rows of Table 5 present difference-in-difference estimates of the impact of LAWA on the rental vacancy rate and the owner-occupied vacancy rate. The synthetic control is

\footnotetext{
${ }^{13}$ A decline in the foreign-born population would impact both the numerator as well as the denominator of the ratio use to calculate the proportion foreign born, and thus a decline in the proportion foreign born of 0.018 implies a slightly smaller percentage population loss. However, to a first approximation assuming a 1.8 percentage point decline is reasonable. Moreover, we are applying the population change to changes in the number of households. To the extent that immigrant households are larger, the implied change in the rental vacancy rate would be smaller than is suggested by this calculation.
} 
quite closely matched to pre-intervention Arizona values, as is evident by the small average differences in vacancy rates for the pre-intervention period. During the post-intervention quarters, the difference in rental vacancy rates between Arizona and synthetic Arizona increase to 5.8 percentage points. Moreover, given the trivial pre-intervention average difference, the difference-in-difference estimate of the impact of LAWA on rental vacancy rates is quite close to the post-treatment difference in means (the DD stands at 5.6 percentage points). Note, this estimate is quite close to the value that we derived from our back-of-the-envelope calculation. Regarding statistical inference, the pre-post LAWA increase in relative rental vacancy rates for Arizona exceeds 45 of the 46 placebo estimates for the pool of donor states, yielding a P-value of 0.043 .

By contrast, there is no evidence of an impact of LAWA on the owner-occupied vacancy rate. There is a slightly negative average pre-intervention difference between Arizona and synthetic Arizona in the owner-occupied vacancy rate that turns slightly positive postintervention. The difference-in-difference estimate suggests that the owner-occupied vacancy rate increases in Arizona by less than half a percentage points. The magnitude of this increase places Arizona $41^{\text {st }}$ out of the 47 states (ranked from smallest to largest values) with an implied P-value of 0.149. Hence, we cannot conclude using the permutation test that the slight increase in the owner-occupied vacancy rate is statistically significant.

C. Testing for heterogeneity in the population response by age and gender

Our final set of results assesses whether the migratory responses to LAWA vary within subsets of the foreign-born population defined by age and gender. There are several reasons that support an a priori expectation for heterogeneity in the impact of the law. First, the fact that LAWA does not apply retroactively to all past hires suggests that those in relatively stable 
employment relationships may be less impacted by the law's enhanced verification requirements. Hence, one might expect greater stability and less of an impact on the relative representation of immigrants among relatively older Arizona residents. Second, children under 16 years of age generally do not work, and hence are not directly impacted by the law. Nonetheless, foreignborn children may be forced to migrate with parents who now face greater difficulty in finding employment as a result of LAWA. Finally, there is a fair degree of gender imbalance in the immigrant population, especially among more recent immigrants from Latin American (Raphael 2010). To the extent that male immigrants are more recent, more likely to be undocumented or perhaps more salient in that they are more likely to seek formal employment, one might expect differential impacts by gender.

Table 6 presents the results from difference-in-difference estimates of the effect of LAWA on the relative proportion in each immigrant category for three age groups: those under 16 years of age, those 16 to 45 years of age, and those 46 years of age and older. Beginning with children, for all three outcomes we observe declines in the proportion immigrant, with most of the decline being concentrated among children that are Hispanic noncitizens. The difference-indifference estimates range from 1.4 to 2 percentage points and in each instance, the value for Arizona is less than all of the placebo estimates for the remaining states. The results for immigrants in the prime working age range (16 to 45 ) are similar yet somewhat larger than the results for children. Point estimates range from relative decline of 2.7 to 2.8 percentage points. Again, the difference-in-difference estimates for Arizona are in the far left tail of the distribution of placebo estimates. We find no evidence of an impact of LAWA on the proportion foreignborn, the proportion noncitizen, nor the proportion Hispanic noncitizen among Arizona residents 46 years and older. 
Finally, Table 7 focuses on the 16 to 45 year age range and presents separate estimates by gender. For the proportion foreign-born outcome, there is some evidence that the law had a larger impact on the representation of immigrants among men in Arizona relative to women, with the male difference-in-difference estimate exceeding the female estimate by one percentage point (in absolute value). However, the estimates for the proportion noncitizen and the proportion noncitizen Hispanic are essentially identical.

\section{Conclusion}

The findings in this study are several. First, we document a notable and statistically significant reduction in the proportion of the Arizona population that is foreign-born and in particular, that is Hispanic noncitizen. The decline observed for Arizona matches the timing of LAWA's implementation, deviates from the time series for the chosen synthetic control group, and stands out relative to the distribution of placebo estimates for the remainder of states in the nation. Second, we do not observe similar declines for Hispanic naturalized citizens, a group not targeted by the legislation. Furthermore, we observe corresponding increases in rental vacancy rates that are quite close to what one would expect based on our estimates of the net population loss. This increase in rental vacancy rates is statistically significant using the standards of the permutation test we employ in this project. Moreover, we do not observe similar increases in the vacancy rate for owner-occupied housing. This is sensible as those most likely to be impacted by the law (undocumented immigrants) are disproportionately concentrated in rental housing.

Finally, we find significant population loss among foreign-born children and working age immigrants with the largest proportional declines observed for those between 16 and 45 years of 
age. We do not find declining representation of the foreign born among Arizona's population that is 46 years of age and older.

While the focus of this paper has been on net changes in the internal composition of the state's population, there are a number of additional questions that naturally arise from the findings that we present. First, in addition to studying the impact of legislation such as LAWA on migration decisions, one might also be concerned with the impact of the law on immigrants (both undocumented as well documented) that remain behind. In particular, the increased use of E-verify in conjunction with the threat of sanctions for employers that do not comply must reduce the proportion of employers willing to hire the undocumented. Among those undocumented immigrants who remain behind, one might expect to observe reductions in employment, increases in informal employment, and perhaps decreases in wages among those who are employed. Moreover, legal immigrants who may not choose to migrate out of Arizona due to LAWA may still experience increased discrimination or E-verify induced bureaucratic hurdles in procuring employment. There is some evidence that the introduction of employment eligibility requirements and employer sanctions with the 1986 passage of IRCA may have caused discrimination against Hispanics legally eligible to work in the U.S. (Bansak and Raphael 2001). The impact of LAWA on the employment outcomes of legal immigrants should certainly be addressed in further research.

Finally, the population changes documented here, and in particular the declining representation of immigrants among the employed, suggests that LAWA may serve as an additional opportunity to study the impact of immigrant labor competition with natives on the employment outcomes of the native born (a la Card 2001, 2005, Borjas 2003, Ottaviano and Peri 2008). LAWA intended to divert labor demand from the unauthorized foreign born to legal 
workers in the state, the majority of which will be comprised of the native born. Further work should focus on theoretically modeling the exact channels through which such demand diversion would impact the employment outcomes of the native born and then empirically estimate the magnitude of any such impacts. 


\section{References}

Abadie, Alberto and Javier Gardeazabal (2003). "The Economic Costs of Conflict: A Case Study of the Basque Country,” American Economic Review, 93(1): 113-132.

Abadie, Alberto; Diamond, Alexis and Jens Hainmueller (2010). "Synthetic Control Methods for Comparative Case Studies: Estimating the Effect of California's Tobacco Control Program,” Journal of the American Statistical Association, 105(490): 493-505.

Arizona Attorney General (2010). Website: Arizona Employers Enrolled in E-Verify, http://www.azag.gov/LegalAZWorkersAct/EVerifyList.html, accessed March 2010.

Bansak, Cynthia and Steven Raphael (2001). "Immigration Reform and the Earnings of Latino Workers: Do Employer Sanctions Cause Discrimination?,” Industrial \& Labor Relations Review, 54(2): 275-295.

Borjas, George J. (2003). “The Labor Demand Curve is Downward Sloping: Reexamining the Impact of Immigration on the Labor Market," Quarterly Journal of Economics, 118(4): 13351374.

Buchmueller, Thomas C, DiNardo, John and Robert G. Valleta (2009). "The Effect of An Employer Health Insurance Mandate on Health Insurance Coverage and the Demand for Labor: Evidence from Hawaii,” Federal Reserve Bank of San Francisco Working Paper \#2009-08.

Card, David (2001). "Immigrant Inflows, Native Outflows, and the Local Labor Market Impacts of Higher Immigration,” Journal of Labor Economics, 19: 22-64.

Card, David (2005). “Is the New Immigration Really so Bad?” National Bureau of Economic Research Working Paper \# 11547.

Los Angeles Times (April 19,2010). Arizona has rarely invoked its last tough immigration law, by Nicole Santa Cruz.

National Conference of State Legislatures (2006). 2006 State Legislation Related to Immigratns: Enacted and Vetoed. Washington DC.

National Conference of State Legislatures (2007). A Review of State Immigration Legislation in 2005. Washington DC.

National Conference of State Legislatures (2008) 2007 Enacted State Legislation Related to Immigrants and Immigration. Washington DC.

National Conference of State Legislatures (2009). 2009 State Laws Related to Immigrants and Immigration. Washington DC.

National Conference of State Legislatures (2009). State Laws Related to Immigrants and Immigration in 2008. Washington DC. 
National Conference of State Legislatures (2010). 2010 State Immigration-Related Bills. Washington DC..

Ottaviano, Gianmarco and Giovanni Peri (2008). "Immigration and National Wages: Clarifying the Theory and Empirics,” Working Paper, University of California, Davis.

Passel, Jeffrey and D’Vera Cohn (2008).” Trends in Unauthorized Immigration: Undocumented Inflow Now Trails Legal Inflow,” Report, Pew Hispanic Center.

Passel, Jeffrey and D'Vera Cohn (2009a). A Portrait of Unauthorized Immigrants in the United States. Washington DC, Pew Hispanic Center.

Passel, Jeffrey and D'Vera Cohn (2009b). “Mexican Immigrants: How Many Come? How Many Leave?” Washington DC, Pew Hispanic Center.

Passel, Jeffrey and D'Vera Cohn (2010). “U.S. Unauthorized Immigration Flows Are Down Sharply Since Mid-Decade” Washington DC, Pew Hispanic Center.

Raphael, Steven (2010). "International Migration, Sex Ratios, and the Socioeconomic Outcomes of Non-Migrant Women,” Institute for Research on Labor and Employment Working paper, UC Berkeley.

Rosenblum, M. (2009). The Basics of E-Verify, the US Employer Verification System. Washington DC, Migration Policy Institute.

Westat (2007). "Finding of the Web Basic Pilot Evaluation,” September. http://www.uscis.gov/files/article/WebBasicPilotRprtSept2007.pdf

Westat (2009). Findings of the E-Verify Program Evaluation. Rockville, MD. 


\section{Figure 1}

Comparison of the Proportion Foreign-Born in Arizona and in the Synthetic Comparison Group, 1998 to 2009

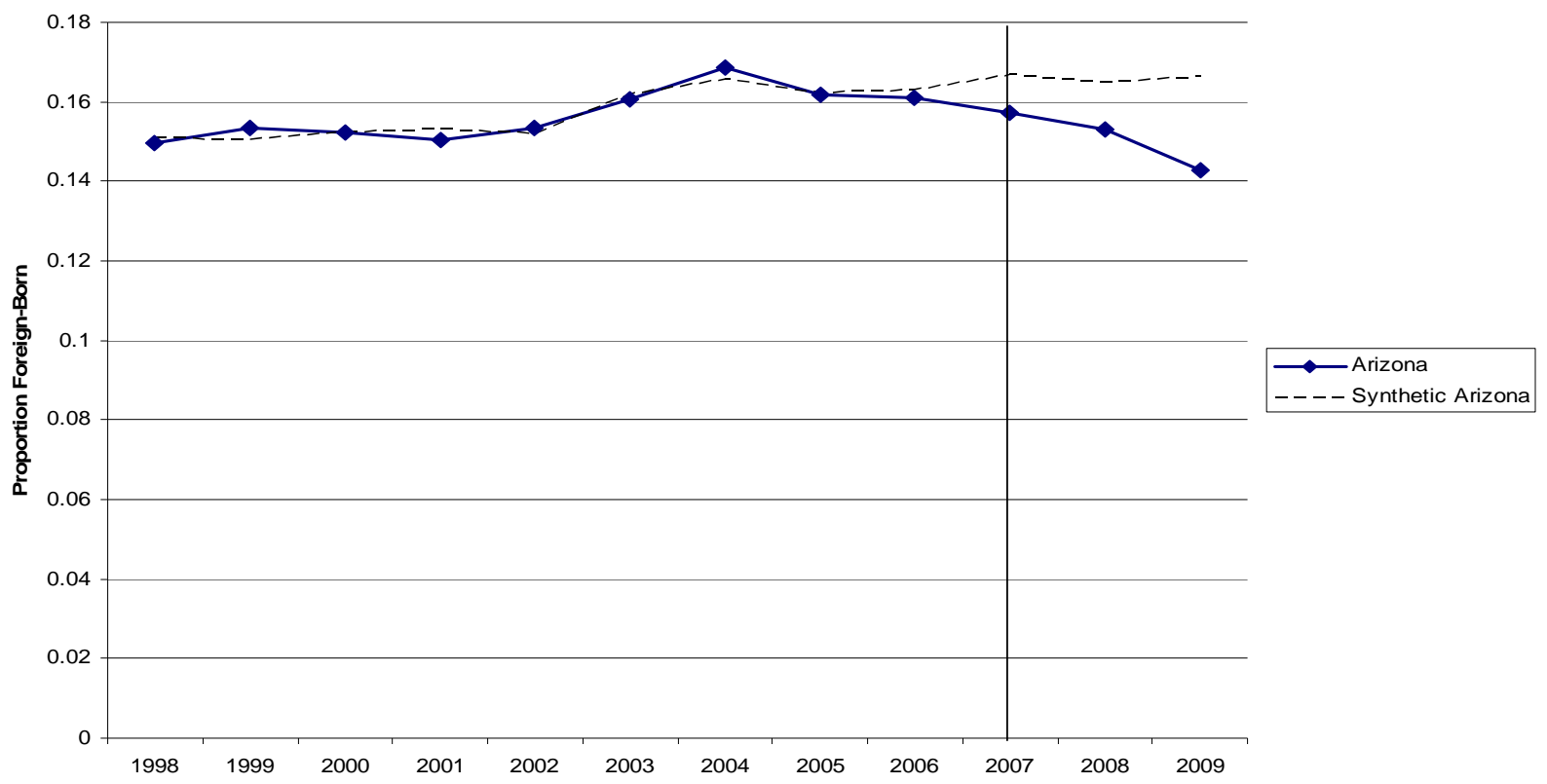

\section{Figure 2}

Comparison of the Proportion Non-Citizen in Arizona and in the Synthetic Comparison Group, 1998 to 2009

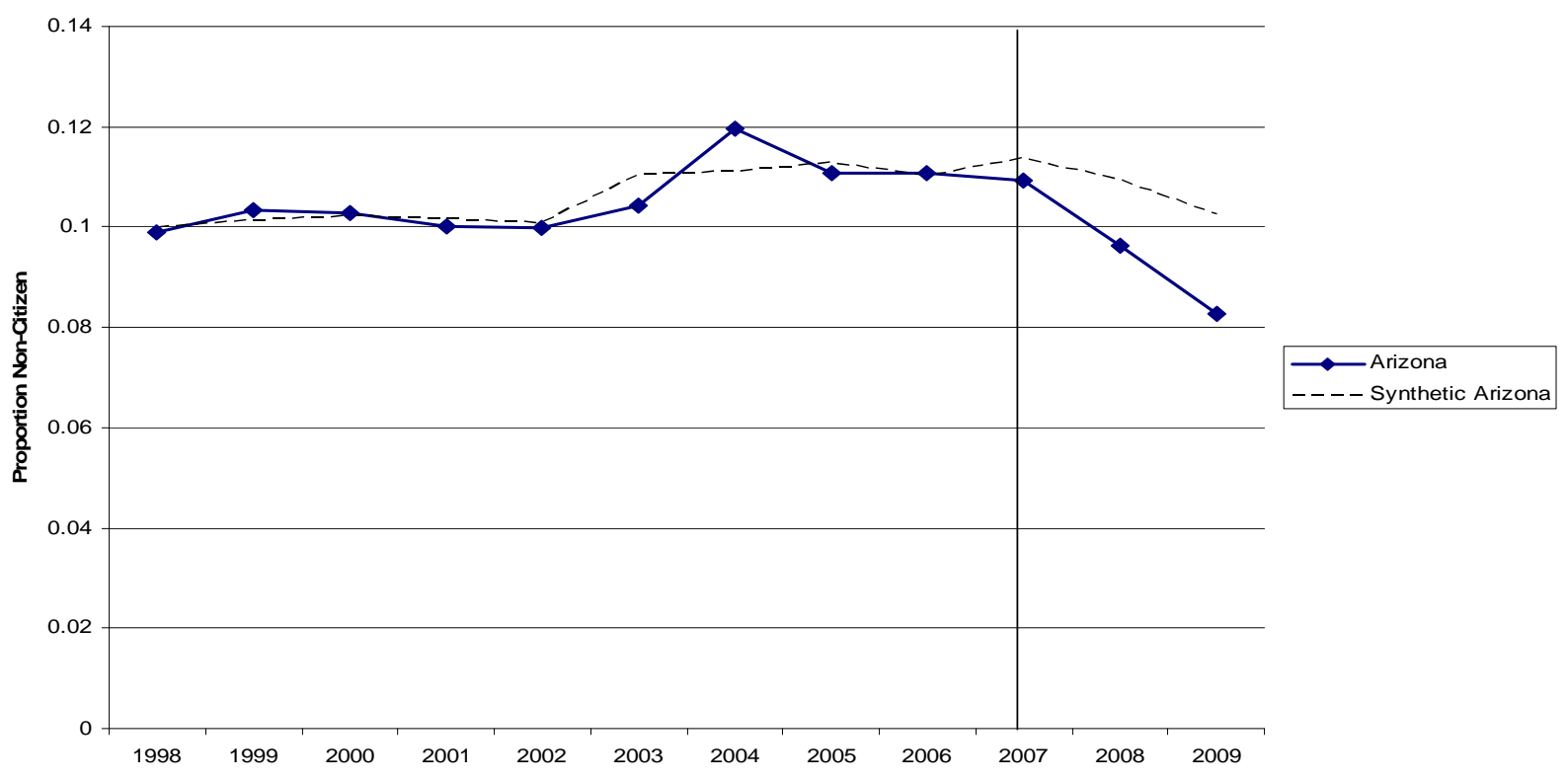


Figure 3

Comparison of the Proportion Non-Citizen Hispanic in Arizona and in the Synthetic Comparison Group

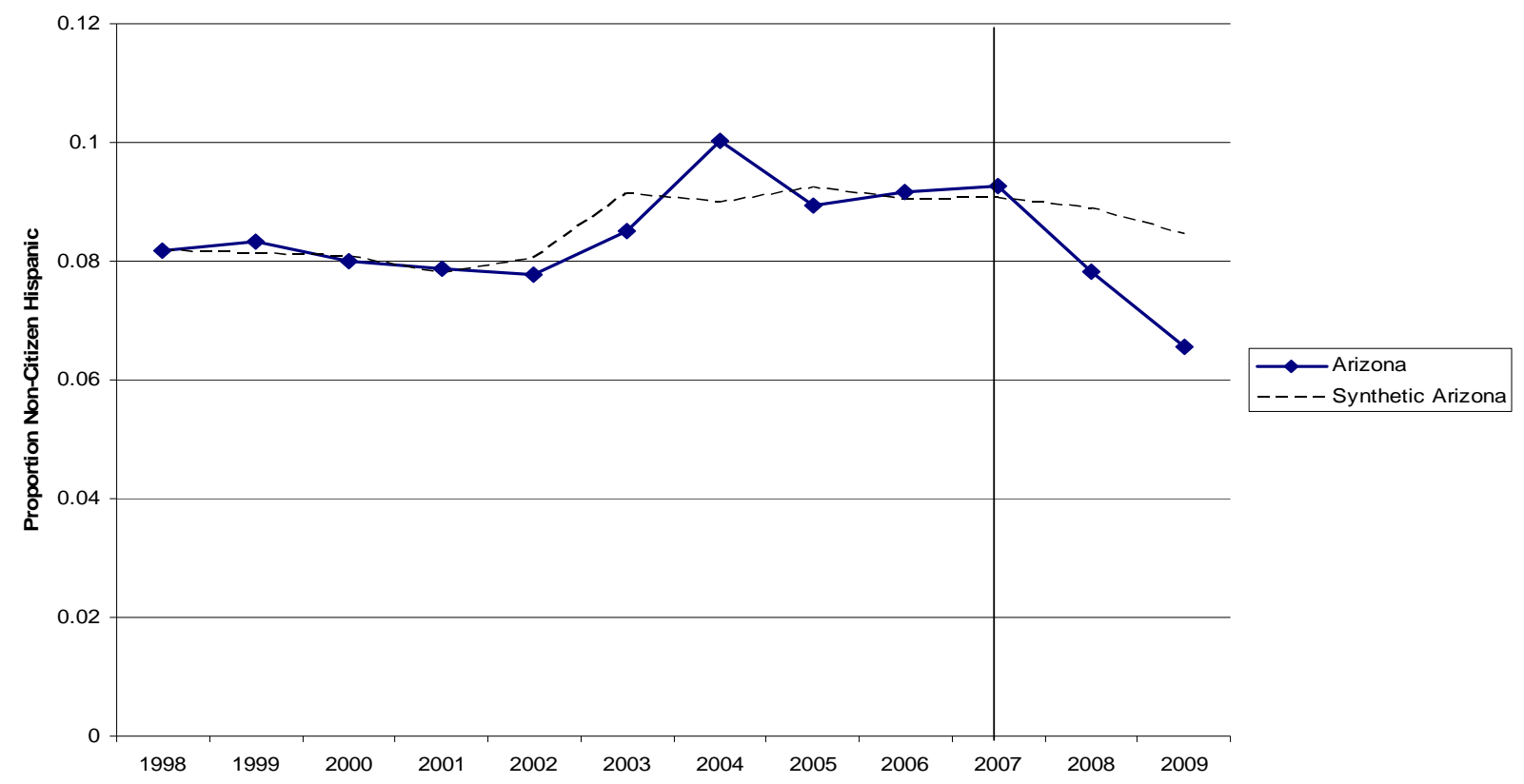

Figure 4: Difference in the Proportion Foreign-Born Relative to the Synthetic Control Group, All States (Arizona Displayed with Thick Red Line)

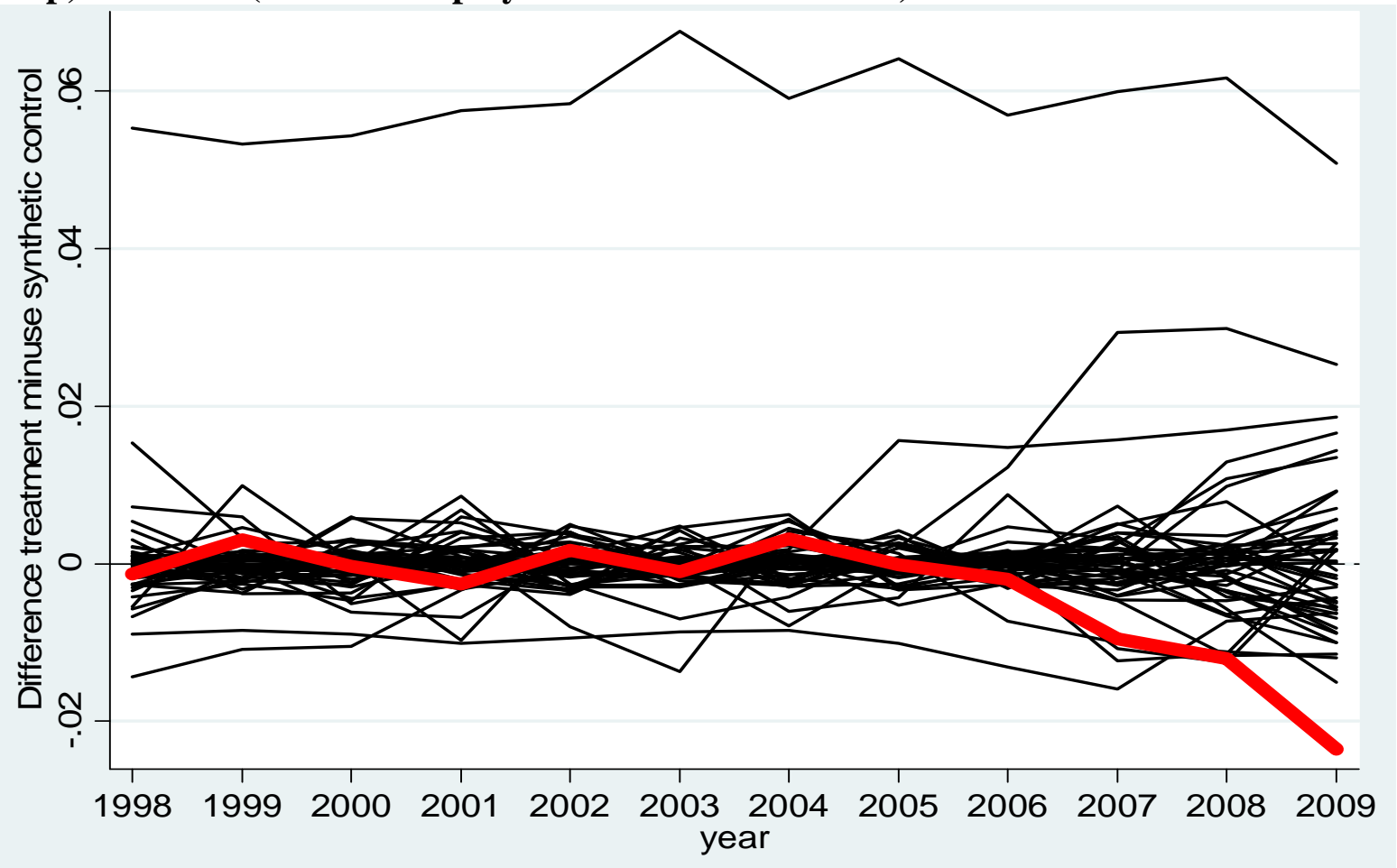


Figure 5: Difference in the Proportion Non-Citizen Relative to the Synthetic Control Group, All States (Arizona Displayed with Thick Red Line)

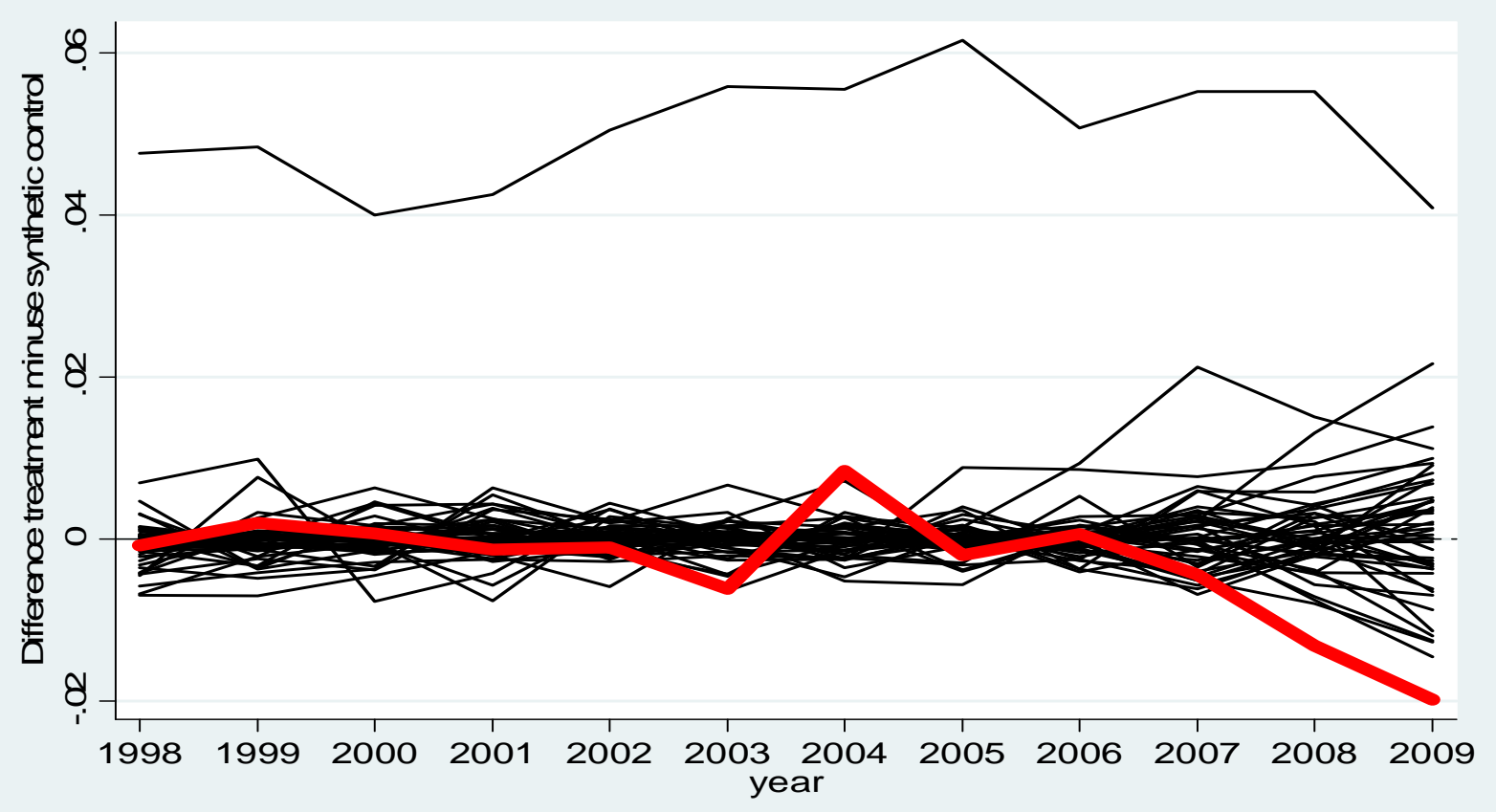

Figure 6: Difference in the Proportion Non-Citizen Hispanic Relative to the Synthetic Control Group, All States (Arizona Displayed with Thick Red Line)

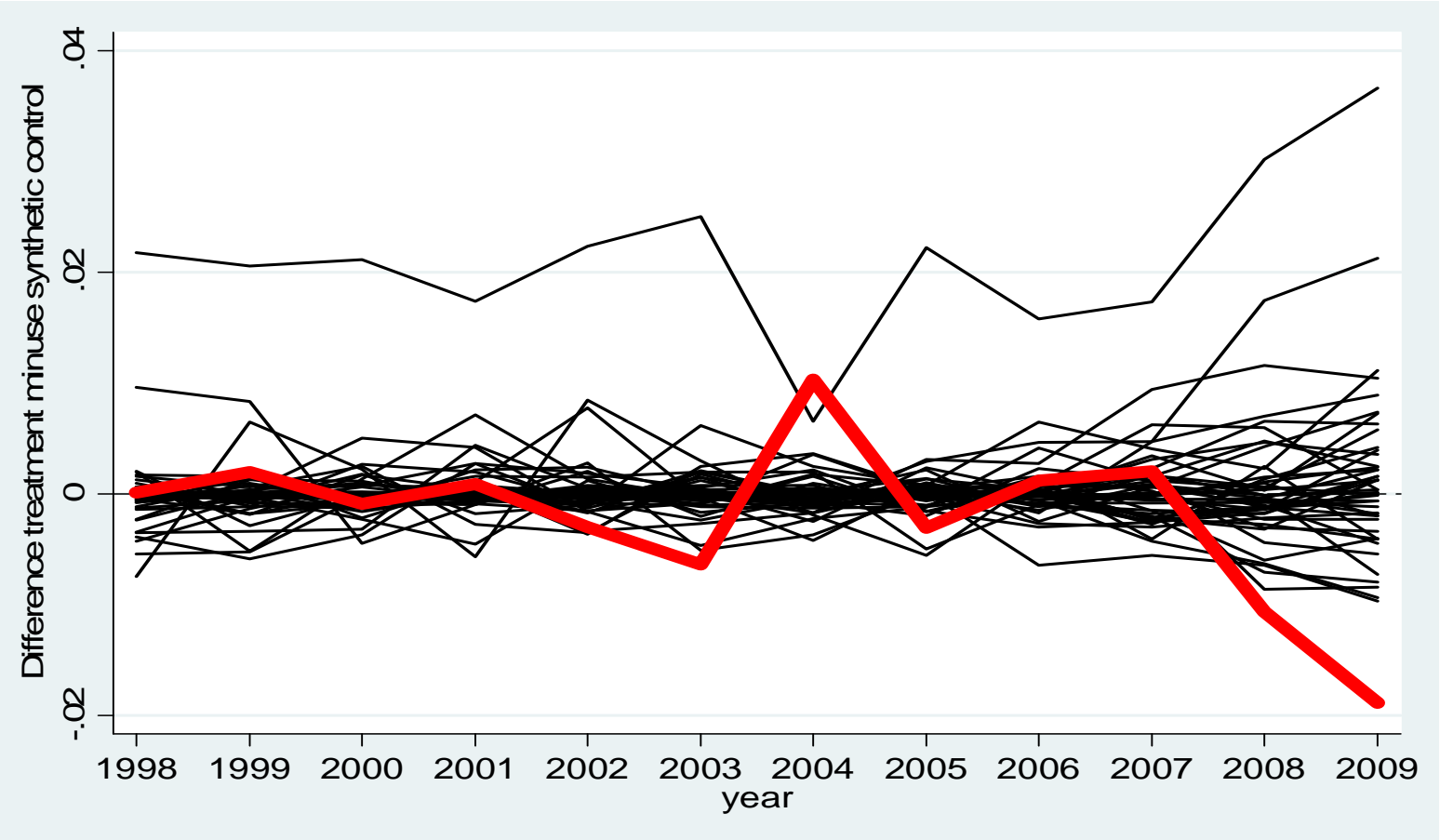


Figure 7

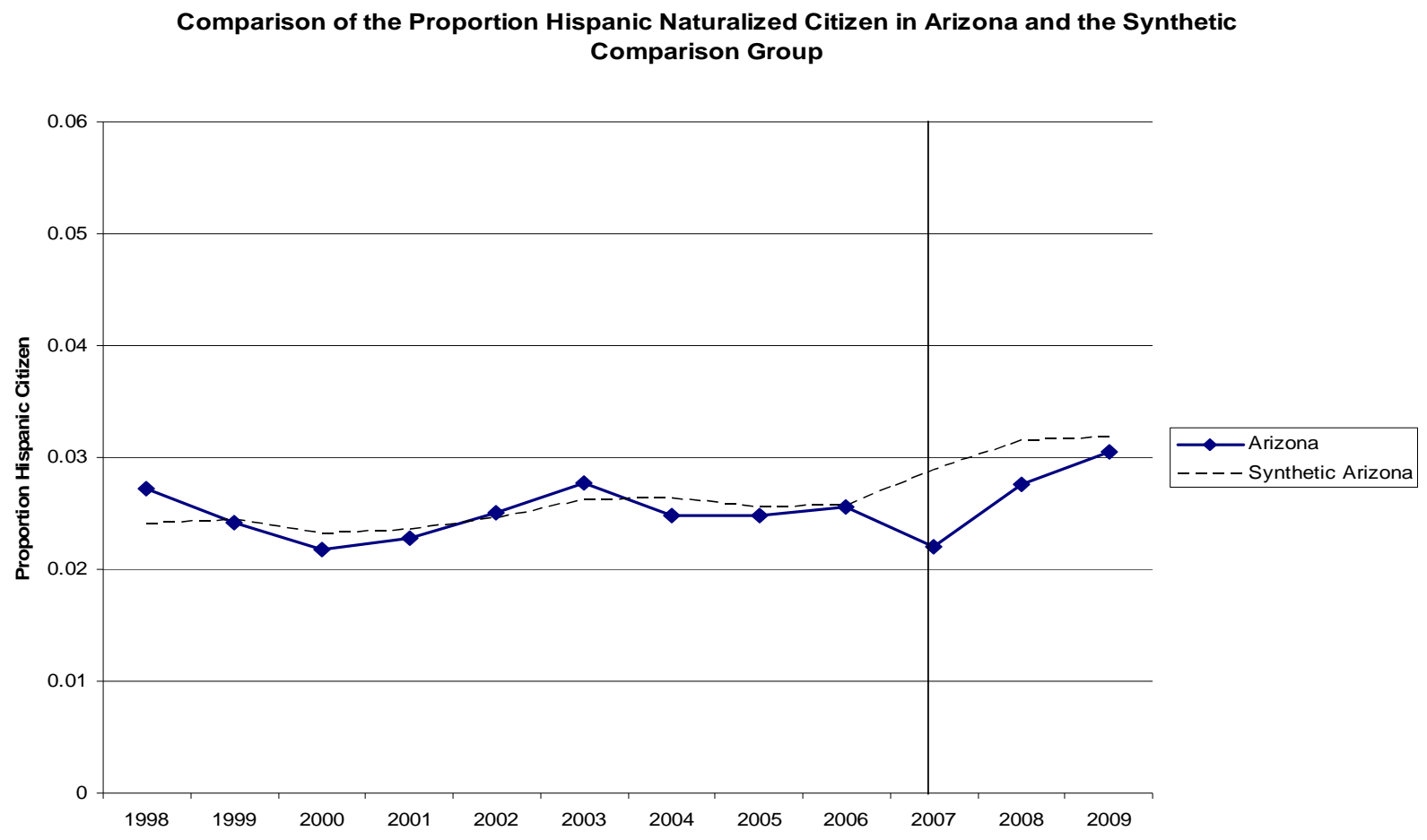

Figure 8: Difference in the Proportion Hispanic Naturalized Citizen Relative to the Synthetic Control Group, All States (Arizona Displayed with Thick Red Line)

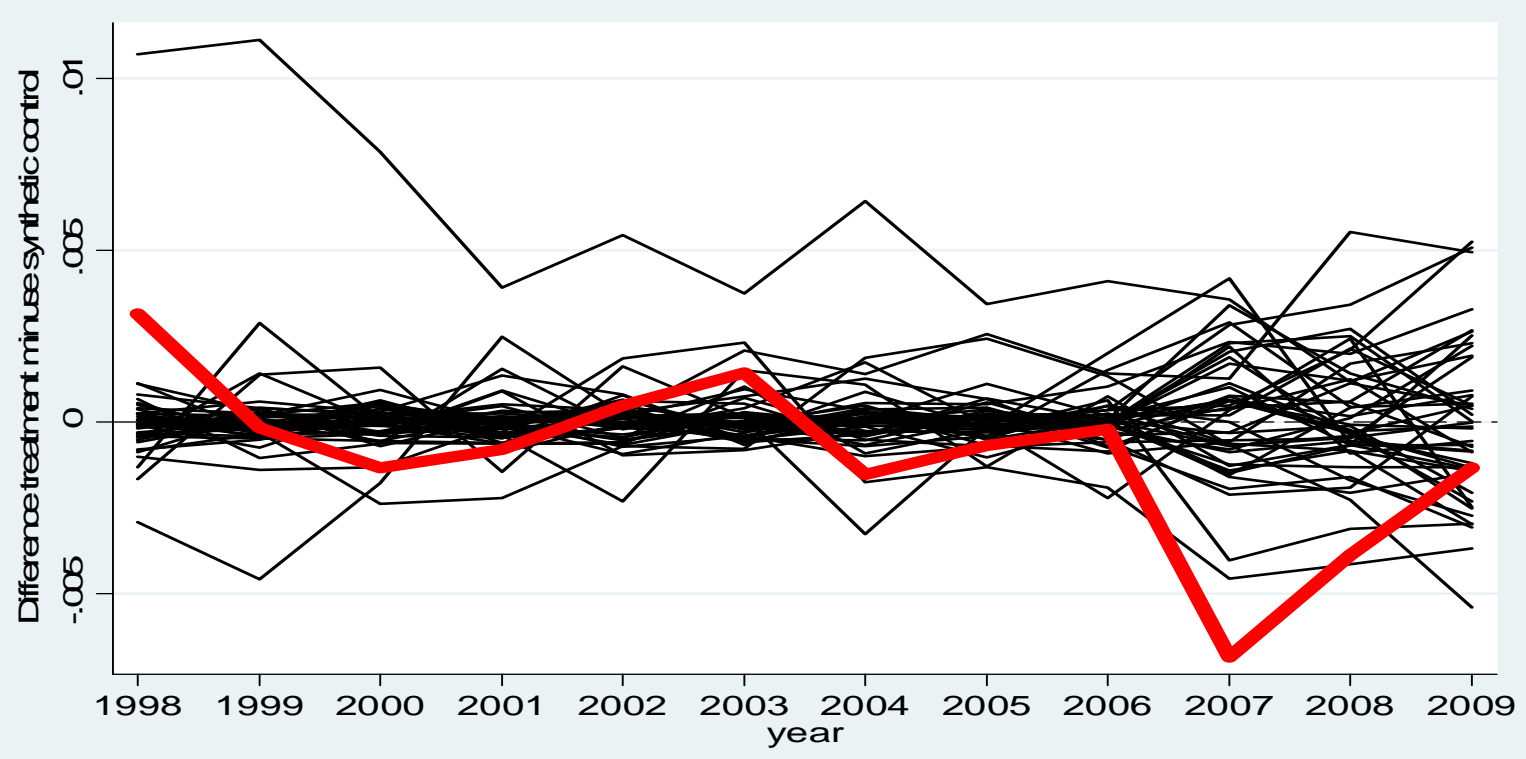


Figure 9

Comparison of Rental Vacancy Rates in Arizona and the Synthetic Comparison Group

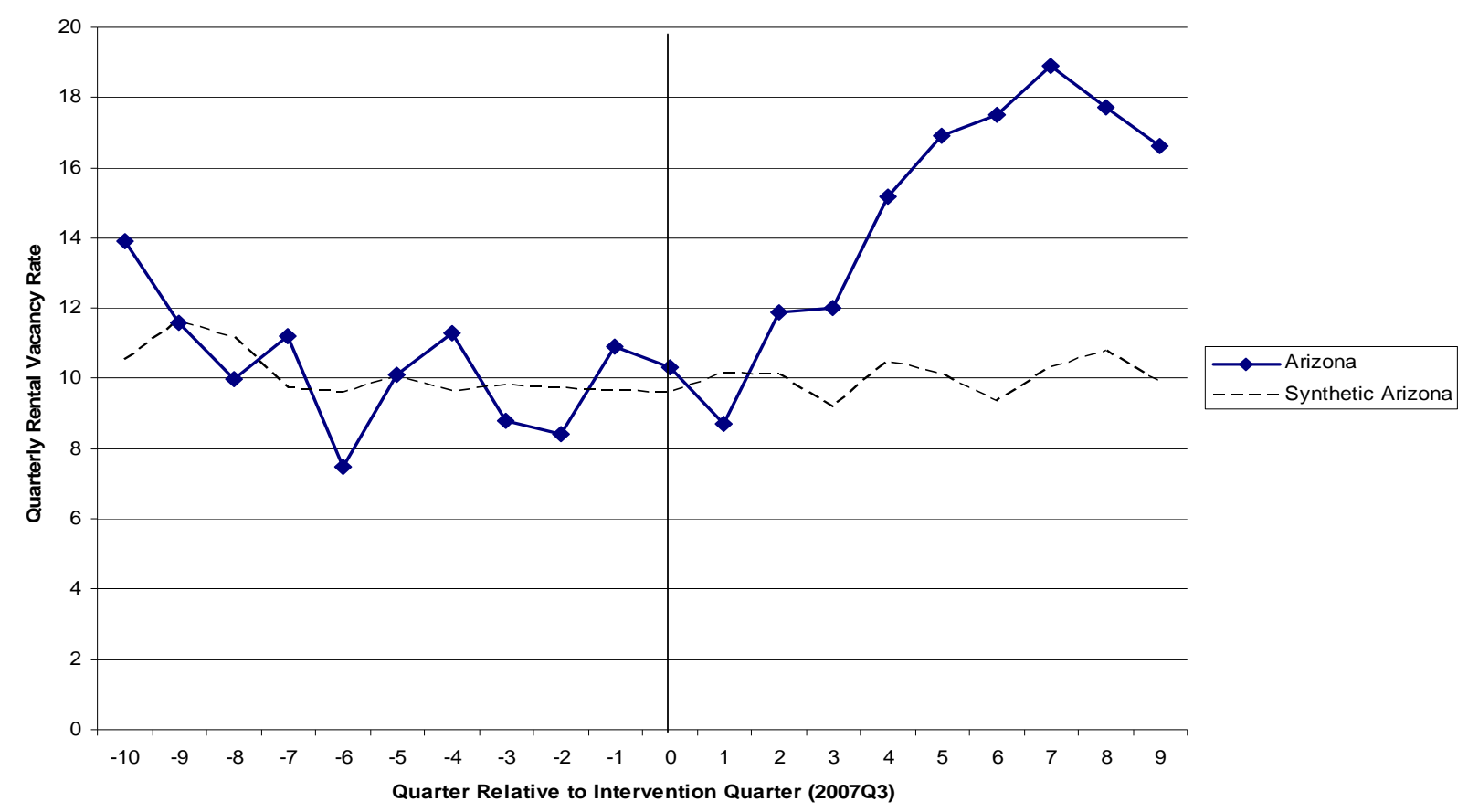

Figure 10: Difference in Rental Vacancy Rates Relative to the Synthetic Control Group, All States (Arizona Displayed with Thick Red Line)

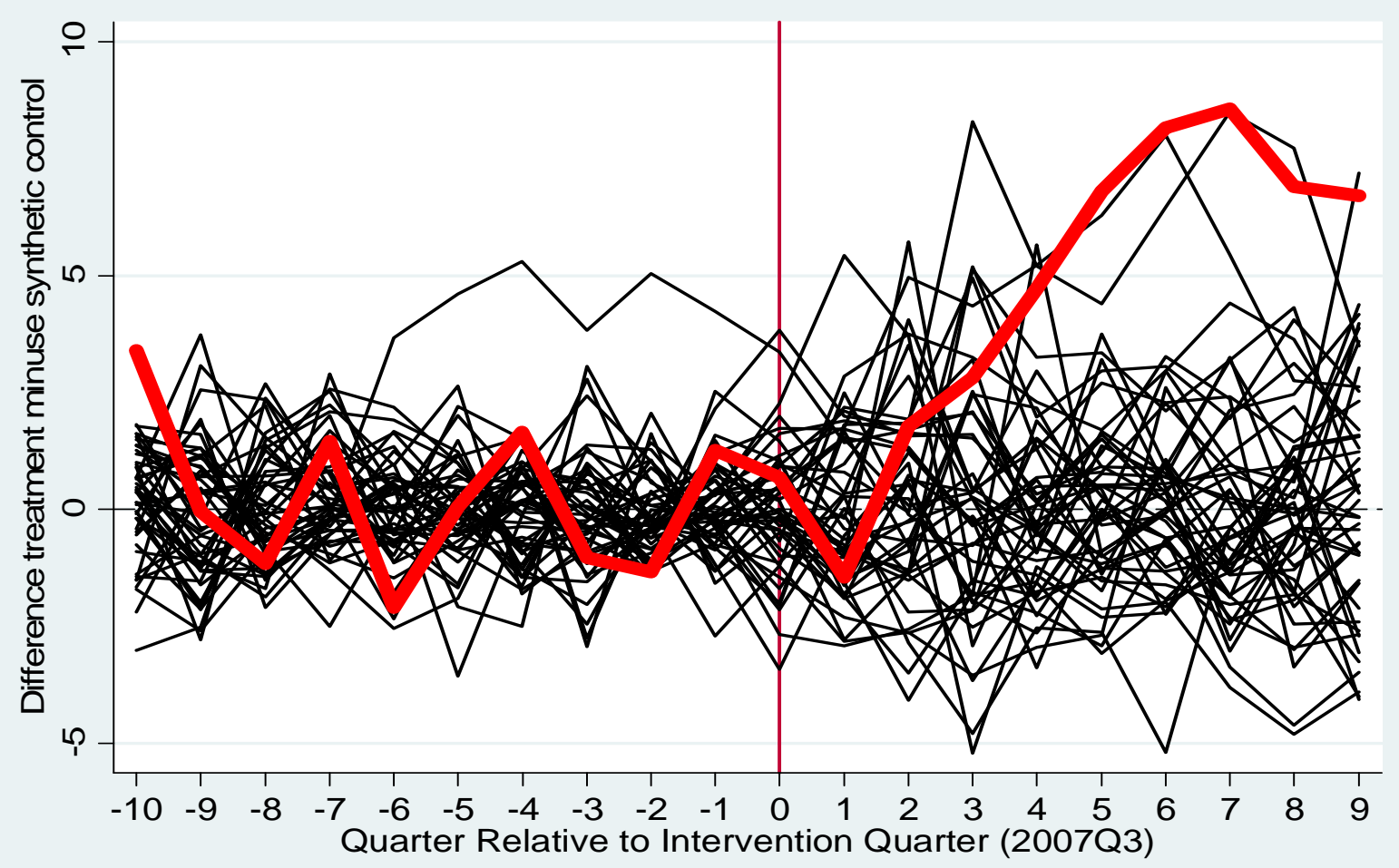


Figure 11

Comparison of Vacancy Rate for Owner-Occupied Housing Units in Arizona and the Synthetic Comparison Group

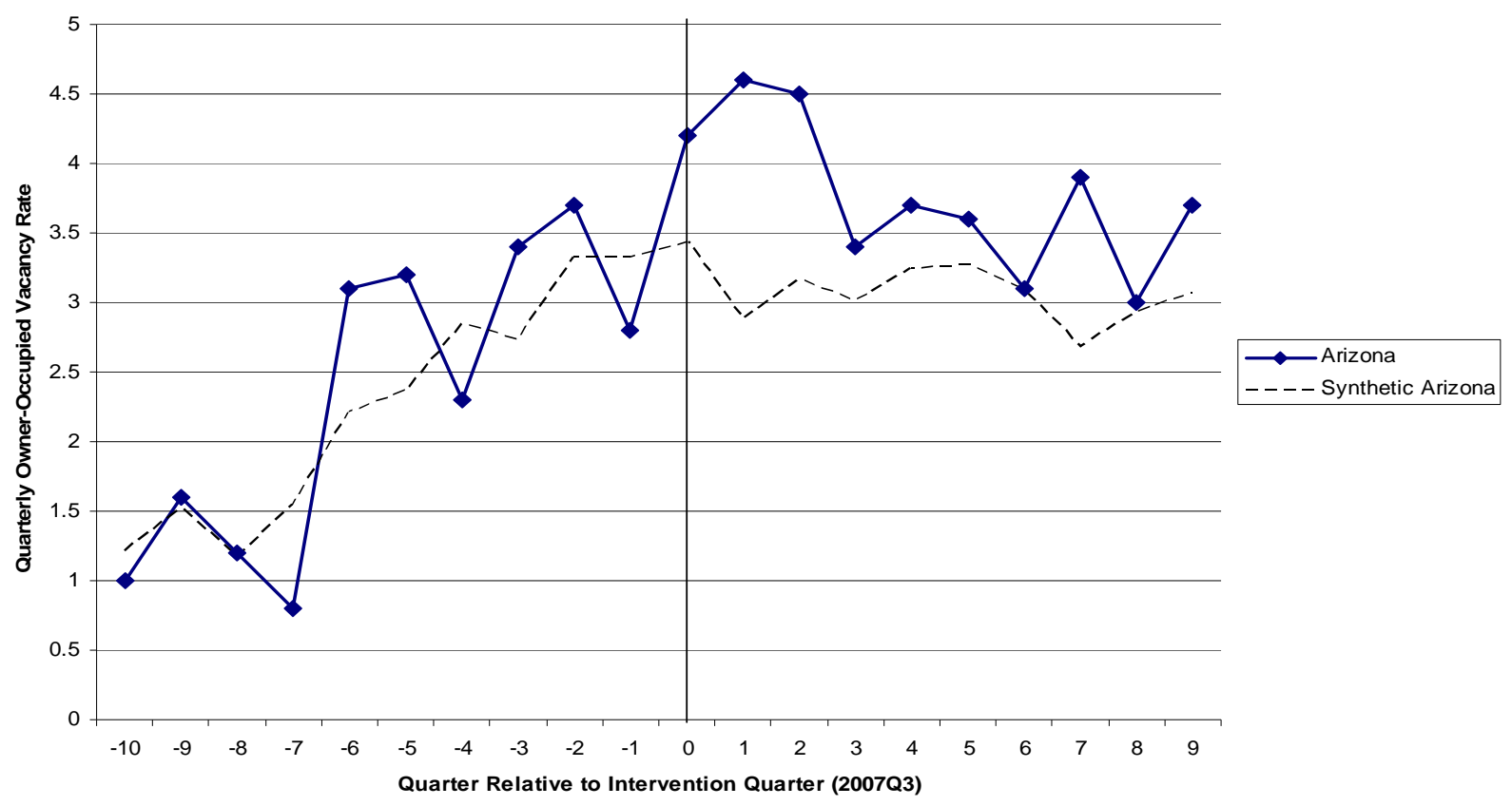

Figure 12: Difference in Owner-Occupied Housing Vacancy Rates Relative to the Synthetic Control Group, All States (Arizona Displayed with Thick Red Line)

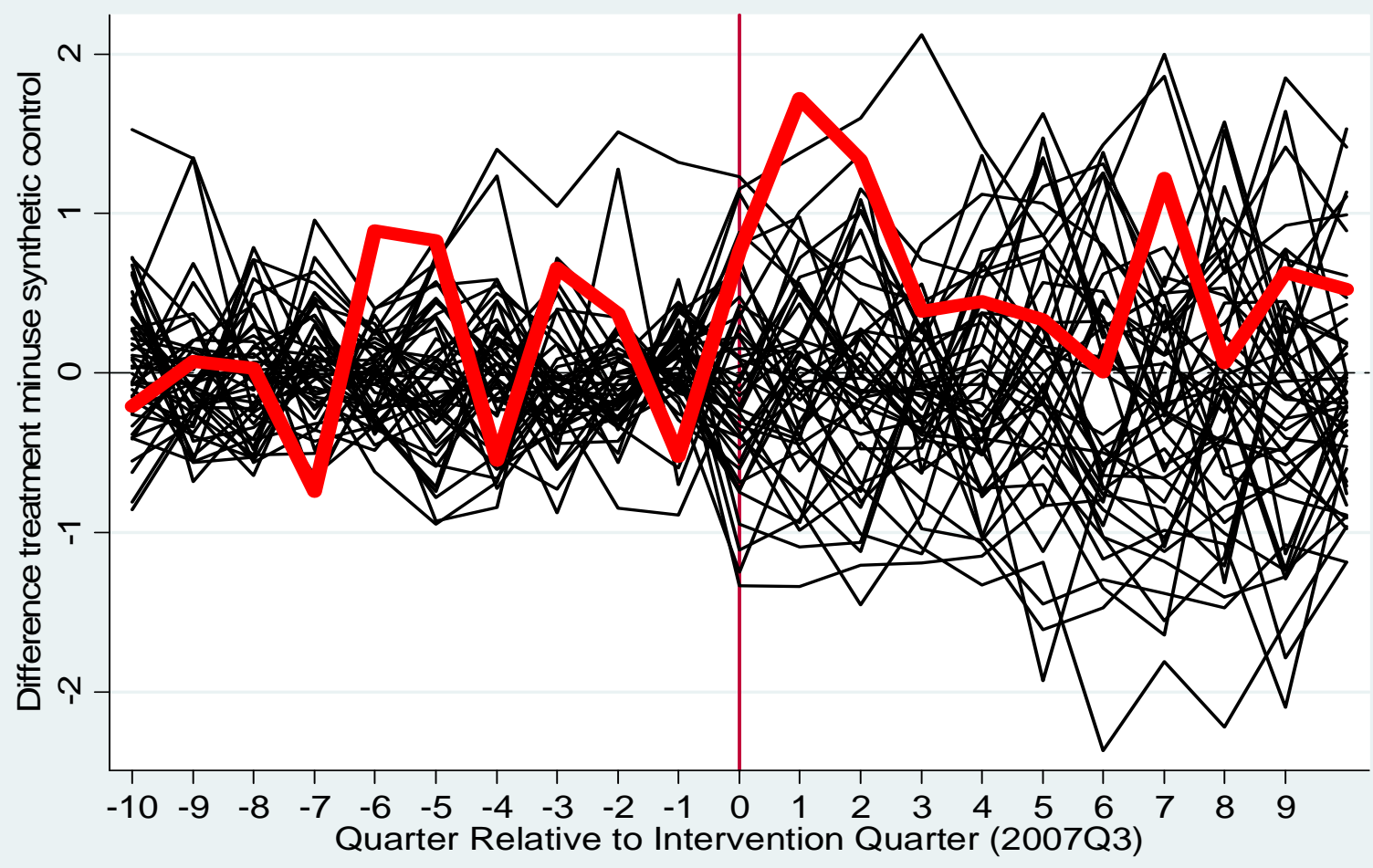




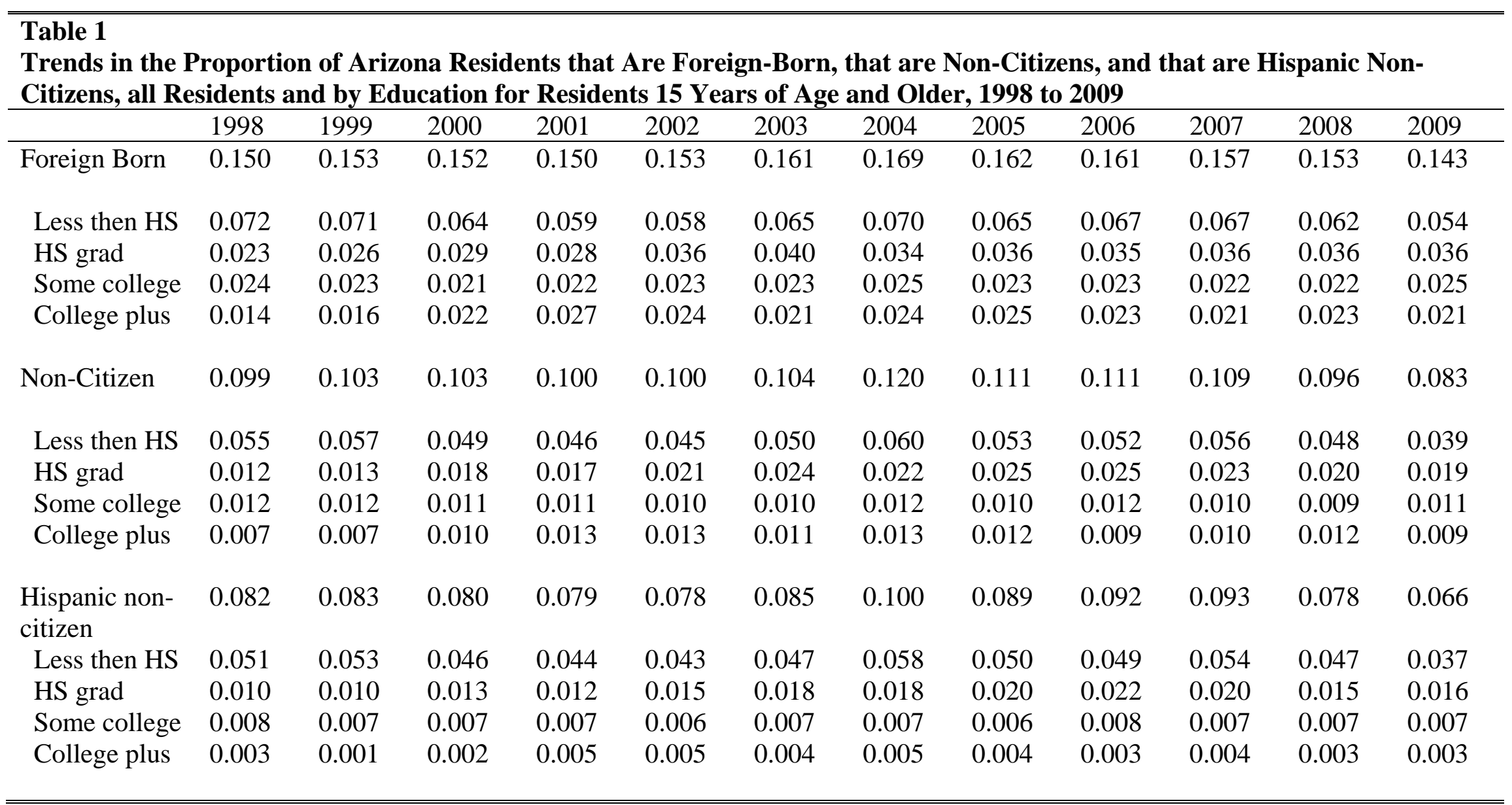

Tabulated using all monthly Current Population Surveys between 1998 and 2009. 
Table 2

States Receiving Positive Weights for the Synthetic Control Groups

\begin{tabular}{|c|c|c|c|c|c|}
\hline \multicolumn{2}{|c|}{ Proportion Foreign-Born } & \multicolumn{2}{|c|}{ Proportion Non-Citizen } & \multicolumn{2}{|c|}{$\begin{array}{l}\text { Proportion Hispanic Non- } \\
\text { citizen }\end{array}$} \\
\hline Alaska & 0.091 & California & 0.441 & California & 0.747 \\
\hline California & 0.161 & DC & 0.028 & Maryland & 0.122 \\
\hline Hawaii & 0.197 & New Jersey & 0.118 & $\begin{array}{l}\text { North } \\
\text { Carolina }\end{array}$ & 0.131 \\
\hline Idaho & 0.034 & $\begin{array}{l}\text { North } \\
\text { Carolina }\end{array}$ & 0.171 & - & - \\
\hline New York & 0.225 & Washington & 0.242 & - & - \\
\hline Oregon & 0.240 & - & - & - & - \\
\hline Washington & 0.145 & - & - & - & - \\
\hline
\end{tabular}

Weights come from the solution to the quadratic-minimization problem displayed in equation (2). 
Table 3

Estimated Impact of the Passage and Introduction of LAWA on Various Sub-Sets of the Foreign-Born Population of Arizona

\begin{tabular}{|c|c|c|c|c|c|}
\hline & $\begin{array}{l}\text { Average diff } \\
\text { relative to } \\
\text { synthetic } \\
\text { cohort, } 9 \text { pre- } \\
\text { intervention } \\
\text { years }\end{array}$ & $\begin{array}{l}\text { Average diff } \\
\text { relative to } \\
\text { synthetic } \\
\text { cohort, } 2008 \\
\text { and } 2009\end{array}$ & $\begin{array}{l}\text { Change, post } \\
\text { minus pre } \\
\text { (Difference- } \\
\text { in-difference } \\
\text { estimate) }\end{array}$ & $\begin{array}{l}\text { Rank, lowest } \\
\text { to highest }\end{array}$ & $\begin{array}{l}\text { P-value from } \\
\text { one-tailed } \\
\text { test, } \\
\mathrm{P}\left(\Delta<\Delta_{\mathrm{AZ}}\right)\end{array}$ \\
\hline \multicolumn{6}{|c|}{ Panel A: As a proportion of all Arizona residents } \\
\hline Foreign-born & 0.000 & -0.018 & -0.018 & $1 / 47$ & 0.021 \\
\hline $\begin{array}{l}\text { Foreign-born } \\
\text { Hispanic }\end{array}$ & 0.000 & -0.021 & -0.021 & $1 / 47$ & 0.021 \\
\hline $\begin{array}{l}\text { Noncitizen } \\
\text { Hispanic }\end{array}$ & 0.000 & -0.015 & -0.015 & $1 / 47$ & 0.021 \\
\hline \multicolumn{6}{|c|}{ Panel B: As a proportion of employed Arizona Residents } \\
\hline Foreign-born & 0.000 & -0.026 & -0.026 & $1 / 47$ & 0.021 \\
\hline $\begin{array}{l}\text { Foreign-born } \\
\text { Hispanic }\end{array}$ & 0.000 & -0.025 & -0.025 & $1 / 47$ & 0.021 \\
\hline $\begin{array}{l}\text { Noncitizen } \\
\text { Hispanic }\end{array}$ & 0.000 & -0.018 & -0.018 & $1 / 47$ & 0.021 \\
\hline
\end{tabular}

Average differences pre and post-intervention are estimates of the difference in the proportion of the Arizona population in the given category relative to the matched synthetic comparison group. The one-tailed test of the significance of the difference-in-difference estimates employ the empirical distribution of the placebo-effect estimates of LAWA for 46 additional states. 
Table 4

Alternative Difference-in-Differences Estimates Including 2007 as a Post-Treatment Year and Excluding States Bordering Arizona from the Potential Pool of Contributing States to the Synthetic Control

\begin{tabular}{|c|c|c|c|c|c|}
\hline & $\begin{array}{l}\text { Average diff } \\
\text { relative to } \\
\text { synthetic } \\
\text { control, pre- } \\
\text { intervention }\end{array}$ & $\begin{array}{l}\text { Average diff } \\
\text { relative to } \\
\text { synthetic } \\
\text { cohort, post- } \\
\text { intervention }\end{array}$ & $\begin{array}{l}\text { Change, post } \\
\text { minus pre } \\
\text { (Difference- } \\
\text { in-difference } \\
\text { estimate) }\end{array}$ & $\begin{array}{l}\text { Rank, lowest } \\
\text { to highest }\end{array}$ & $\begin{array}{l}\text { P-value from } \\
\text { one-tailed } \\
\text { test, } \\
\mathrm{P}\left(\Delta<\Delta_{\mathrm{AZ}}\right)\end{array}$ \\
\hline \multicolumn{6}{|c|}{ Panel A: Including 2007 as a Post-Treatment Year } \\
\hline Foreign-born & 0.000 & -0.015 & -0.015 & $1 / 47$ & 0.021 \\
\hline Noncitizen & 0.000 & -0.012 & -0.013 & $1 / 47$ & 0.021 \\
\hline $\begin{array}{l}\text { Noncitizen } \\
\text { Hispanic }\end{array}$ & 0.000 & -0.009 & -0.009 & $1 / 47$ & 0.021 \\
\hline \multicolumn{6}{|c|}{ Panel B: Dropping States that Border Arizona from the Donor Pool } \\
\hline Foreign-born & 0.000 & -0.019 & -0.019 & $1 / 43$ & 0.023 \\
\hline Noncitizen & 0.002 & -0.014 & -0.016 & $1 / 43$ & 0.023 \\
\hline $\begin{array}{l}\text { Noncitizen } \\
\text { Hispanic }\end{array}$ & 0.008 & -0.014 & -0.022 & $1 / 43$ & 0.023 \\
\hline
\end{tabular}

Average differences pre and post-intervention are estimates of the difference in the proportion of the Arizona population in the given category relative to the matched synthetic comparison group. The one-tailed test of the significance of the difference-in-difference estimates employ the empirical distribution of the placebo-effect estimates of LAWA for 46 additional states in panel $\mathrm{A}$ and 42 additional states in panel $\mathrm{B}$.

a. For the estimates in panel A, the post-intervention period includes the years 2007, 2008, and 2009. For the estimates in Panel B, the post-intervention period includes the years 2008 and 2009 
Table 5

Estimated Impact of the Passage and Introduction of LAWA on Hispanic Naturalized Citizens, on Rental Vacancy Rates and on Vacancy Rates for Owner-Occupied Housing

\begin{tabular}{|c|c|c|c|c|c|}
\hline & $\begin{array}{l}\text { Average pre- } \\
\text { intervention } \\
\text { difference } \\
\text { relative to the } \\
\text { synthetic } \\
\text { control }^{\text {a }}\end{array}$ & $\begin{array}{l}\text { Average post- } \\
\text { intervention } \\
\text { difference } \\
\text { relative to the } \\
\text { synthetic } \\
\text { control }^{\text {b }}\end{array}$ & $\begin{array}{l}\text { Change, post } \\
\text { minus pre } \\
\text { (Difference- } \\
\text { in-difference } \\
\text { estimate) }\end{array}$ & $\begin{array}{l}\text { Rank, lowest } \\
\text { to highest }\end{array}$ & $\begin{array}{l}\text { P-value from } \\
\text { one-tailed } \\
\text { test }^{\mathrm{c}}\end{array}$ \\
\hline $\begin{array}{l}\text { Proportion } \\
\text { Hispanic } \\
\text { Naturalized } \\
\text { Citizen }\end{array}$ & 0.000 & -0.003 & -0.003 & $5 / 47$ & 0.106 \\
\hline $\begin{array}{l}\text { Rental } \\
\text { Vacancy Rate }\end{array}$ & 0.217 & 5.809 & 5.592 & $46 / 47$ & 0.043 \\
\hline $\begin{array}{l}\text { Owner- } \\
\text { Occupied } \\
\text { Vacancy Rate }\end{array}$ & 0.085 & 0.554 & 0.469 & $41 / 47$ & 0.149 \\
\hline
\end{tabular}

Average differences pre and post-intervention are estimates of the difference in the outcome for Arizona relative to the matched synthetic comparison group. The one-tailed test of the significance of the difference-in-difference estimates employ the empirical distribution of the placebo-effect estimates of LAWA for 46 additional states.

a. The pre-intervention values for the proportion Hispanic naturalized citizen outcome are the annual values for the period 1998 through 2006. The pre-intervention values for the vacancy rate outcomes are the quarterly values for the period 2005Q1 through 2007Q2.

b. For all outcomes, the post intervention period pertains to 2008 and 2009. For the rental vacancy rates, the post-intervention values are measured quarterly while for the proportion naturalized Hispanic citizen, the values are annual.

c. Values in this column are the p-values of a one-tailed test of the null that the Arizona DD estimate is non-negative against the alternative of a negative value for the proportion of residents that are Hispanic naturalized citizens. For the housing vacancy rates, the test statistics are the pvalues of a one-tailed test of the null hypothesis that the vacancy rates are non-positive against the alternative of an increase in vacancy rates. 
Table 6

Estimated Impact of the Passage and Introduction of LAWA on Various Sub-Sets of the Foreign-Born Population by Broad Age Groups

\begin{tabular}{|c|c|c|c|c|c|}
\hline & $\begin{array}{l}\text { Average diff } \\
\text { relative to } \\
\text { synthetic } \\
\text { cohort, } 9 \text { pre- } \\
\text { intervention } \\
\text { years }\end{array}$ & $\begin{array}{l}\text { Average diff } \\
\text { relative to } \\
\text { synthetic } \\
\text { cohort, } 2008 \\
\text { and } 2009\end{array}$ & $\begin{array}{l}\text { Change, post } \\
\text { minus pre } \\
\text { (Difference- } \\
\text { in-difference } \\
\text { estimate) }\end{array}$ & $\begin{array}{l}\text { Rank, lowest } \\
\text { to highest }\end{array}$ & $\begin{array}{l}\text { P-value from } \\
\text { one-tailed } \\
\text { test, } \\
\mathrm{P}\left(\Delta<\Delta_{\mathrm{AZ}}\right)\end{array}$ \\
\hline \multicolumn{6}{|c|}{ Panel A: Population under 16} \\
\hline Foreign-born & 0.001 & -0.018 & -0.019 & $1 / 47$ & 0.021 \\
\hline Noncitizen & 0.001 & -0.019 & -0.020 & $1 / 47$ & 0.021 \\
\hline $\begin{array}{l}\text { Noncitizen } \\
\text { Hispanic }\end{array}$ & 0.006 & -0.008 & -0.014 & $1 / 47$ & 0.021 \\
\hline \multicolumn{6}{|c|}{ Panel B: Population 16 to 45} \\
\hline Foreign-born & 0.000 & -0.027 & -0.027 & $1 / 47$ & 0.021 \\
\hline Noncitizen & 0.000 & -0.027 & -0.027 & $1 / 47$ & 0.021 \\
\hline $\begin{array}{l}\text { Noncitizen } \\
\text { Hispanic }\end{array}$ & 0.000 & -0.028 & -0.028 & $1 / 47$ & 0.021 \\
\hline \multicolumn{6}{|c|}{ Panel C: Population 46 and Older } \\
\hline Foreign-born & 0.000 & 0.000 & 0.000 & $30 / 47$ & 0.638 \\
\hline Noncitizen & 0.000 & -0.005 & -0.005 & $10 / 47$ & 0.2121 \\
\hline $\begin{array}{l}\text { Noncitizen } \\
\text { Hispanic }\end{array}$ & 0.000 & -0.001 & -0.001 & $11 / 47$ & 0.234 \\
\hline
\end{tabular}

Average differences pre and post-intervention are estimates of the difference in the proportion of the Arizona population in the given category relative to the matched synthetic comparison group. The one-tailed test of the significance of the difference-in-difference estimates employ the empirical distribution of the placebo-effect estimates of LAWA for 46 additional states. 
Table 7

Estimated Impact of the Passage and Introduction of LAWA on Various Sub-Sets of the Prime Working Age Foreign-Born Population by Gender

\begin{tabular}{|c|c|c|c|c|c|}
\hline & $\begin{array}{l}\text { Average diff } \\
\text { relative to } \\
\text { synthetic } \\
\text { cohort, } 9 \text { pre- } \\
\text { intervention } \\
\text { years }\end{array}$ & $\begin{array}{l}\text { Average diff } \\
\text { relative to } \\
\text { synthetic } \\
\text { cohort, } 2008 \\
\text { and } 2009\end{array}$ & $\begin{array}{l}\text { Change, post } \\
\text { minus pre } \\
\text { (Difference- } \\
\text { in-difference } \\
\text { estimate) }\end{array}$ & $\begin{array}{l}\text { Rank, lowest } \\
\text { to highest }\end{array}$ & $\begin{array}{l}\text { P-value from } \\
\text { one-tailed } \\
\text { test, } \\
\mathrm{P}\left(\Delta<\Delta_{\mathrm{AZ}}\right)\end{array}$ \\
\hline \multicolumn{6}{|c|}{ Panel A: Males 14 to 65 Years of Age } \\
\hline Foreign-born & 0.000 & -0.035 & -0.035 & $2 / 47$ & 0.043 \\
\hline Noncitizen & 0.001 & -0.026 & -0.026 & $1 / 47$ & 0.021 \\
\hline $\begin{array}{l}\text { Noncitizen } \\
\text { Hispanic }\end{array}$ & 0.000 & -0.021 & -0.022 & $2 / 47$ & 0.043 \\
\hline \multicolumn{6}{|c|}{ Panel B: Female 14 to 65 Years of Age } \\
\hline Foreign-born & 0.000 & -0.025 & -0.025 & $1 / 47$ & 0.021 \\
\hline Noncitizen & 0.000 & -0.026 & -0.026 & $1 / 47$ & 0.021 \\
\hline $\begin{array}{l}\text { Noncitizen } \\
\text { Hispanic }\end{array}$ & 0.001 & -0.021 & -0.023 & $1 / 47$ & 0.021 \\
\hline
\end{tabular}

Average differences pre and post-intervention are estimates of the difference in the proportion of the Arizona population in the given category relative to the matched synthetic comparison group. The one-tailed test of the significance of the difference-in-difference estimates employ the empirical distribution of the placebo-effect estimates of LAWA for 46 additional states. 


\section{Appendix}

Figure A1: Annual Employment Growth in Arizona and Bordering States, 1999-2009

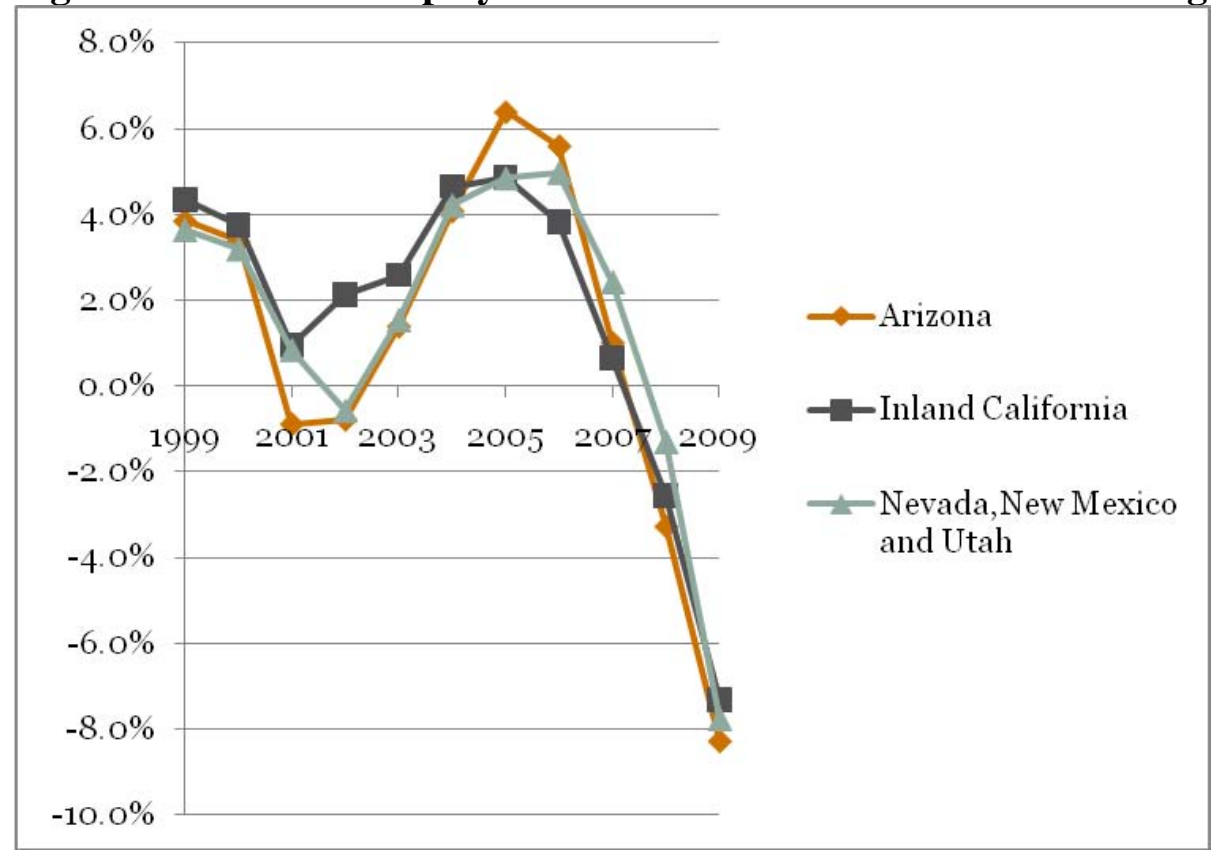

SOURCE: Author's calculations from the 1998-2009 Quarterly Census of Employment and Wages (QCEW)

Figure A2: Annual Employment Growth in Construction in Arizona and Bordering States, 1999-2009

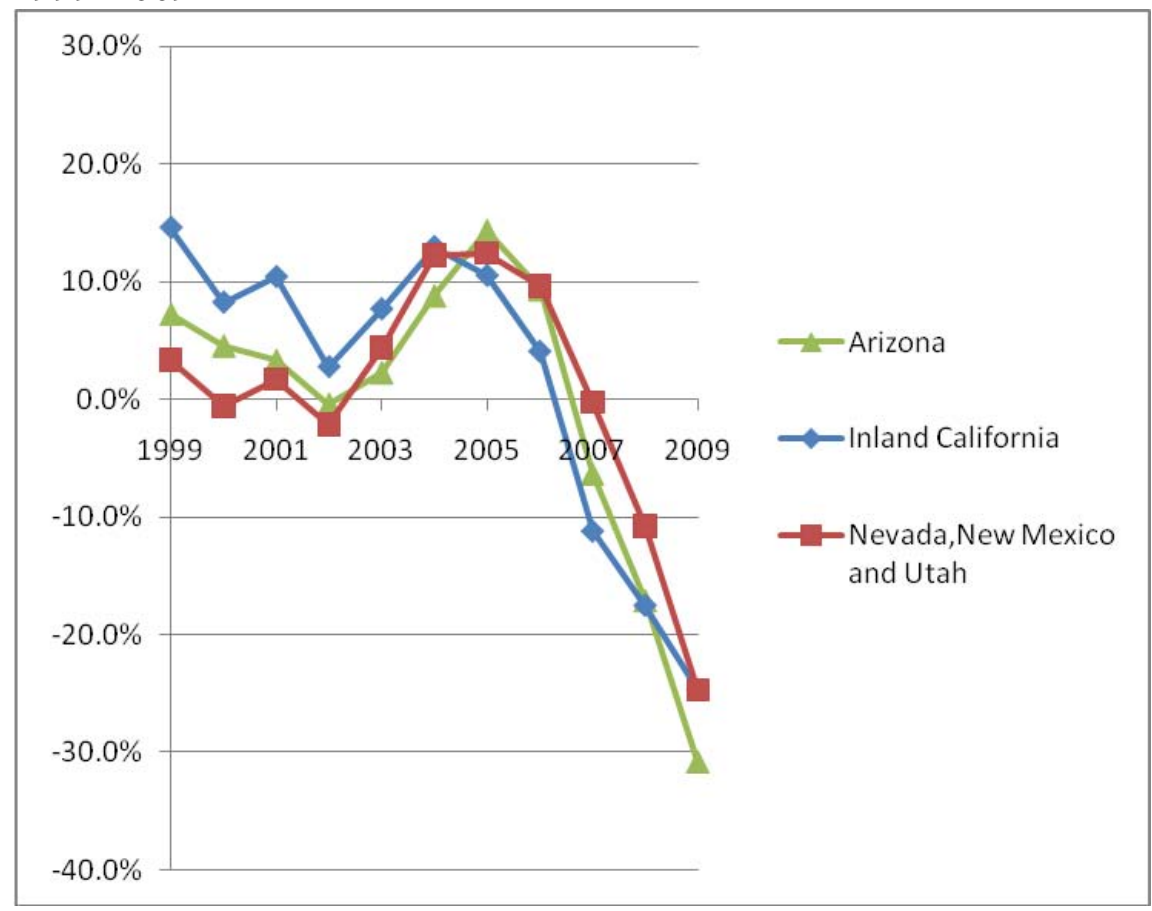

SOURCE: Author’s calculations from the 1998-2009 Quarterly Census of Employment and Wages (QCEW) 